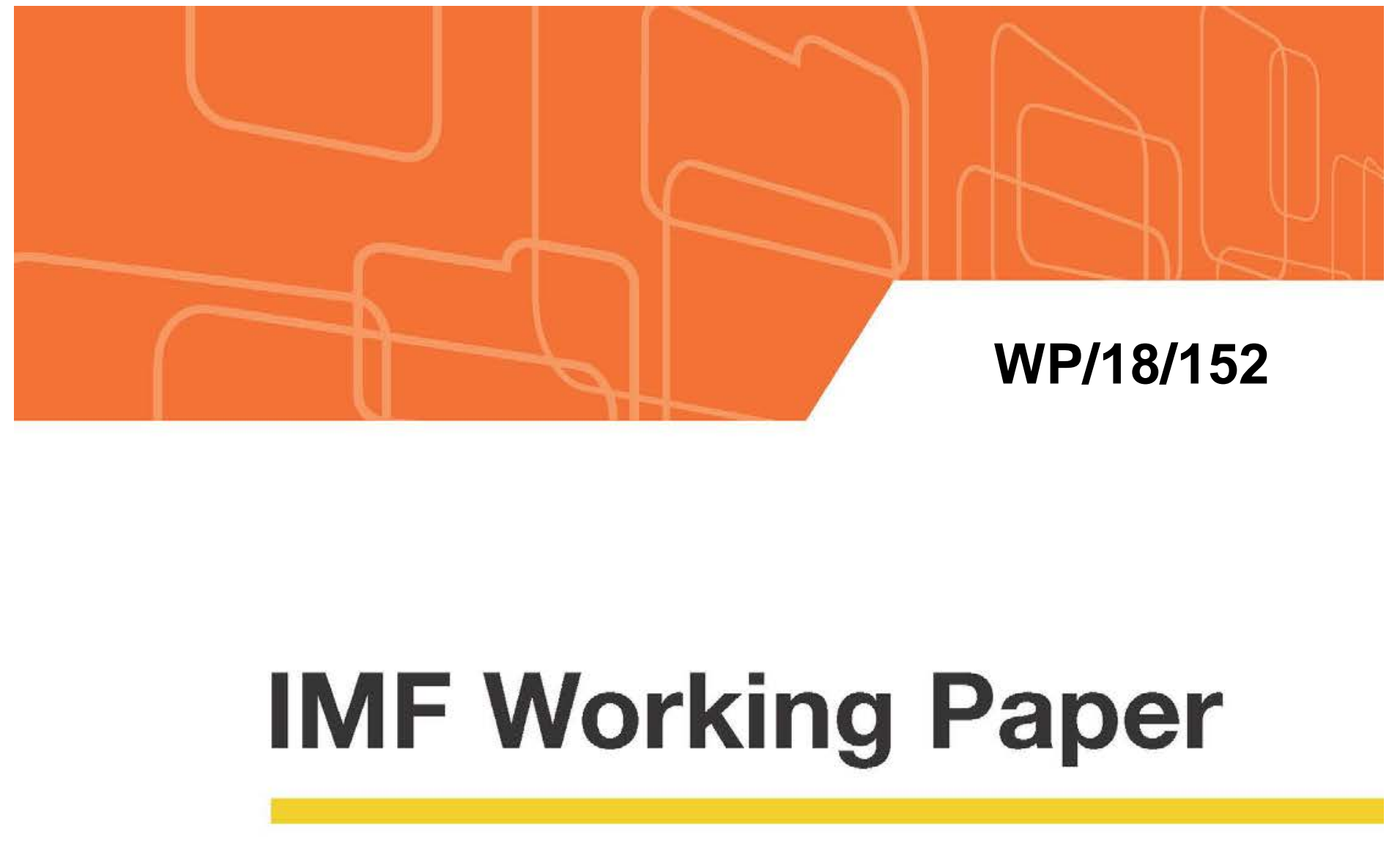

\title{
Estimates of Potential Output and the Neutral Rate for the U.S. Economy
}

by Ali Alichi, Rania Al-Mashat, Hayk Avetisyan, Jaromir Benes, Olivier Bizimana, Aram Butavyan, Robert Ford, Narek Ghazaryan,

Vahagn Grigoryan, Mane Harutyunyan, Anahit Hovhannisyan, Edgar Hovhannisyan, Hayk Karapetyan, Mariam Kharaishvili, Douglas Laxton, Akaki Liqokeli, Karolin Matikyan, Gevorg Minasyan, Shalva Mkhatrishvili, Armen Nurbekyan, Andrei Orlov, Babken Pashinyan, Garik Petrosyan, Yekaterina Rezepina, Aleksandr Shirkhanyan, Tamta Sopromadze, Lusine Torosyan, Erik Vardanyan, Hou Wang, and Jiaxiong Yao 


\title{
IMF Working Paper
}

\author{
Research Department
}

\section{Estimates of Potential Output and the Neutral Rate for the U.S. Economy}

\begin{abstract}
Prepared by Ali Alichi, Rania Al-Mashat, Hayk Avetisyan, Jaromir Benes, Olivier Bizimana, Aram Butavyan, Robert Ford, Narek Ghazaryan, Vahagn Grigoryan, Mane Harutyunyan, Anahit Hovhannisyan, Edgar Hovhannisyan, Hayk Karapetyan, Mariam Kharaishvili, Douglas Laxton, Akaki Liqokeli, Karolina Matikyan, Gevorg Minasyan, Shalva Mkhatrishvili, Armen Nurbekyan, Andrei Orlov, Babken Pashinyan, Garik Petrosyan, Yekaterina Rezepina, Aleksandr Shirkhanyan, Tamta Sopromadze, Lusine Torosyan, Erik Vardanyan, Hou Wang, and Jiaxiong Yao ${ }^{1}$
\end{abstract}

Authorized for distribution by Douglas Laxton

April 2018

IMF Working Papers describe research in progress by the author(s) and are published to elicit comments and to encourage debate. The views expressed in IMF Working Papers are those of the author(s) and do not necessarily represent the views of the IMF, its Executive Board, or IMF management.

\begin{abstract}
Estimates of potential output and the neutral short-term interest rate play important roles in policy making. However, such estimates are associated with significant uncertainty and subject to significant revisions. This paper extends the structural multivariate filter methodology by adding a monetary policy block, which allows estimating the neutral rate of interest for the U.S. economy. The addition of the monetary policy block further improves the reliability of the structural multivariate filter.
\end{abstract}

JEL Classification Numbers: C51, E31, E52

Keywords: Macroeconomic Modeling, Potential Output, Neutral Rate Author’s E-Mail Address (selected): AAlichi@imf.org; RAlMashat@imf.org; OBizimana@imf.org; DLaxton@imf.org; Armen.Nurbekyan@cba.am; HWang2@imf.org; JYao@imf.org

\footnotetext{
${ }^{1}$ The estimates of potential output and the output gap presented in this paper are not official IMF estimates. The programs and potential output estimates can be downloaded from www.douglaslaxton.org.
} 


\section{Table of Contents}

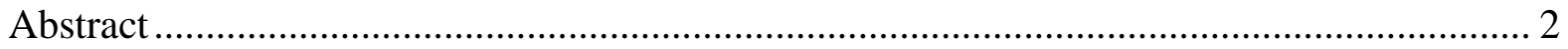

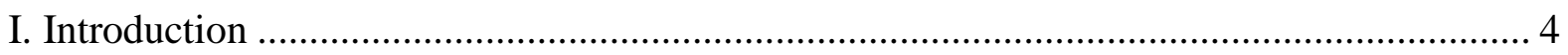

II. MPMOD

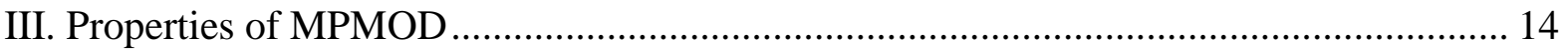

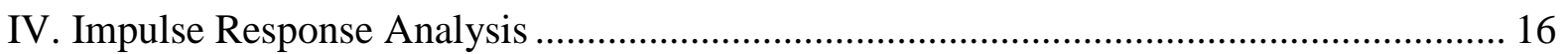

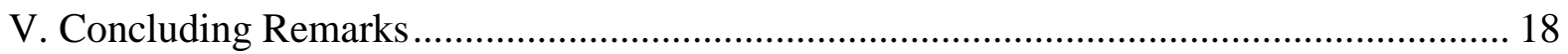

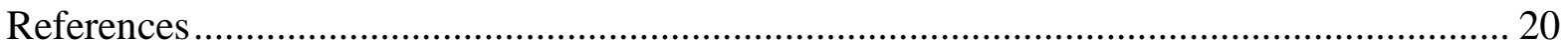

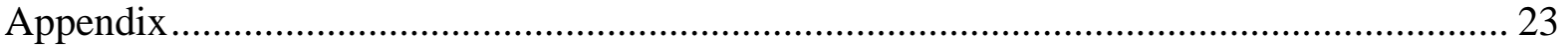

A. MPMOD Equations.................................................................................................. 23

B. MPMOD Parameters, Shock Distribution, and Data Source ......................................... 28

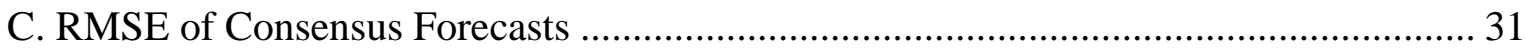

\section{Figures}

Figure 1. Comparison of MPMOD Estimates with CBO Estimates........................................ 8

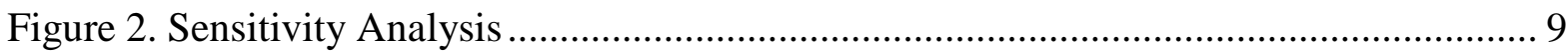

Figure 3. Real-time Estimates and Rolling Forecasts ........................................................... 10

Figure 4. Comparison of Multivariate Filter Results with and without the Monetary Policy

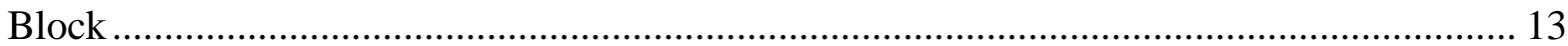

Figure 5. MPMOD Detailed Results............................................................................. 14

Figure 6. Impulse Response for a 1-Standard-Deviation Positive Shock to the Output Gap 17 Figure 7. Impulse Response for a 1-Standard-Deviation Positive Shock to the Level of Potential Output .............................................................................................................. 17 Figure 8. Impulse Response for a 1-Standard-Deviation Positive Shock to the Growth Rate of Potential Output .......................................................................................................... 18 Figure 9. Impulse Response for a 1-Standard-Deviation Negative Shock to the Inflation

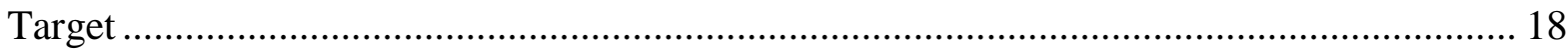

\section{Appendix Figures}

Figure A1. Shocks to the Level and Growth Rate of Potential Output, and to the Output Gap

\section{Appendix Tables}

Table B1. Estimation Results for Structural Model Parameters ............................................... 28

Table B2. Estimation Results for Shock Distributions ............................................................. 29

Table B3. Data Sources.................................................................................................... 30 


\section{INTRODUCTION}

Estimates of potential output and the output gap are both difficult to produce, but key for macroeconomic policy making. ${ }^{2}$ Accordingly, the subject has generated a large academic and policy literature. This paper builds on the work by Alichi and others (2017), who developed a structural multivariate filter that brings to bear a Phillips curve, a dynamic Okun's law, and an equation that links the output gap to capacity utilization. ${ }^{3}$ They showed that the structural multivariate filter outperforms univariate filters, such as the Hodrick-Prescott (HP) filter, in that it provides more reliable real-time estimates of potential output and the output gap. The advantage of a structural multivariate filter over an HP-type filter is that the multivariate filter incorporates structural relationships between macroeconomic fundamentals, and is flexible to incorporate additional information (such as capacity utilization, inflation expectations, and in the model presented below, monetary policy).

This paper extends the multivariate filter methodology by adding a monetary policy block. This block brings in short- and long-term interest rates (i.e., the term structure), and a monetary policy reaction function to capture policy responses to relevant cyclical developments. This addition provides us with a fuller and more structural description of the dynamics of the output gap, compared to the earlier models in which the policy response was, at best, implicit. The model developed in this paper estimates a deeper and prolonged post-global-financial-crisis output gap compared with the same model without a monetary policy block.

The remainder of the paper is organized as follows. Section II summarizes the new model, called MPMOD (short for Monetary Policy Model), discusses key relationships, and reports the estimation results. Section III compares model results against a univariate filter, and against a multivariate filter without a monetary policy block. Section IV presents the impulse response analysis. Section V concludes.

\footnotetext{
${ }^{2}$ For monetary policy, such estimates are critical for managing the short-run output-inflation tradeoff (see Clinton and others, 2015).

${ }^{3}$ The original multivariate filter was first developed by Laxton and Tetlow (1992) and has been extended and applied to a number of countries. For example, Benes and others (2010), Blagrave and others (2015), Alichi (2015), and Alichi and others (2015). It is important to note that this empirical work has been based on linearized versions of the Phillips curve. For a discussion of nonlinearities and their related policy implications, see Laxton, Rose and Tetlow (1993a, b), Laxton, Ricketts and Rose (1993), Debelle and Laxton (1997), Isard, Laxton and Eliasson (1999), Clark, Laxton and Rose (1995, 2001), Argov and others (2007), and Alichi and others (2009).
} 


\section{MPMOD}

MPMOD is an extension of the multivariate filter model presented in Alichi and others (2017). The original model includes a Phillips curve, a dynamic Okun’s law equation linking the unemployment gap to the output gap (Okun, 1962), and an equation linking the output gap to the Fed's measure of capacity utilization in the manufacturing sector. The stochastic process for GDP includes a persistent cyclical component as well as two shocks that permanently change the level of potential output (a level shift, and a persistent, though not permanent, deviation from the long-term growth rate). In this paper, we extend that model to include a monetary policy reaction function for interest rate on the one-year government bond and a model for the 10-year government bond yield. This allows us to estimate and project both the short-term (one-year) equilibrium real interest rate and the 10-year government bond term premium.

The details of the model are provided in Appendix A, and only the new monetary block is discussed in this section. The list of standard macro variables includes real GDP, the unemployment rate, consumer price inflation, the Fed's survey of manufacturing capacity utilization, the one-year government bond yield, and the 10-year government bond yield.

The output gap $\left(\hat{y}_{t}\right)$ is defined as the deviation of real GDP, in log terms $\left(y_{t}\right)$, from its potential level $\left(\bar{y}_{t}\right)$ :

$$
\hat{y}_{t}=y_{t}-\bar{y}_{t}
$$

The stochastic process for real GDP is defined by three equations, (2)-(4), and three types of shocks:

$$
\begin{aligned}
& \bar{y}_{t}=\bar{y}_{t-1}+g_{\bar{y}, t}+\epsilon_{\bar{y}, t} \\
& g_{\bar{y}, t}=\left(1-\rho_{g_{\bar{y}}}\right) g_{\bar{y}, t-1}+\rho_{g_{\bar{y}}} g_{\bar{y}}^{s S}+\epsilon_{g_{\bar{y}}, t} \\
& \hat{y}_{t}=\phi_{1} \hat{y}_{t-1}-\phi_{2} \widehat{r r}_{t}^{1 Y}-\phi_{3} \widehat{r r}_{t-1}^{1 Y}+\phi_{4} \epsilon_{g_{\bar{y}}, t}-\phi_{5} \epsilon_{\bar{y}, t}+\epsilon_{\hat{y}, t}
\end{aligned}
$$

The level of potential output $\left(\bar{y}_{t}\right)$ evolves according to a stochastic process for trend potential growth $\left(g_{\bar{y}, t}\right)$ and a simple level-shock term $\left(\epsilon_{\bar{y}, t}\right)$. Trend potential growth is subject to shocks $\left(\epsilon_{g_{\bar{y}}, t}\right)$ whose impact fades gradually away depending on the parameter $\rho_{g_{\bar{y}}}$ (a lower value of which means a slower adjustment back to the steady-state growth rate following a shock). Both the shock to trend potential growth $\left(\epsilon_{g_{\bar{y}}, t}\right)$ and the shock to the level of potential output $\left(\epsilon_{\bar{y}, t}\right)$ result in unit roots in potential output and GDP. 
Finally, the output gap $\left(\hat{y}_{t}\right)$ is a function of contemporaneous and lagged values of the oneyear real interest rate gap $\left(\widehat{r r}_{t}^{1 Y}\right)$, which in turn is the deviation of the short-term interest rate from its equilibrium level. The output gap equation also incorporates shocks to trend potential growth $\left(\epsilon_{g_{\bar{y}}, t}\right)$ and shocks to the level of potential output $\left(\epsilon_{\bar{y}, t}\right)$. The specification intends to replicate the insights from structural DSGE models, where anticipated increases in future productivity growth $\left(\epsilon_{g_{\bar{y}}, t}\right)$ can, in the short-to-medium term, result in larger increases in aggregate demand than potential output as consumers and firms respond to higher expected levels of future income and demand (Juillard and others, 2007). In the same DSGE models, pure level shocks to potential output $\left(\epsilon_{\bar{y}, t}\right)$ that raise productivity once and for all reduce the marginal costs of production and inflation in the short run. GDP is also subject to demand shocks $\left(\epsilon_{\hat{y}, t}\right)$, which raise aggregate demand in the economy by more than potential.

Equation (5) is the monetary policy interest rate reaction function. The one-year nominal interest rate $\left(r s_{t}^{1 Y}\right)$ responds to the deviation of inflation $\left(\pi_{t}\right)$ from target $\left(\pi_{t}^{T a r}\right)$ and the output gap $(\hat{y})$. The reaction function captures the dual mandate of the Federal Reserve:

$$
\begin{aligned}
& r s_{t}^{1 Y}=\alpha_{1} r s_{t-1}^{1 Y} \\
& +\left(1-\alpha_{1}\right)\left[\overline{r r}_{t}^{1 Y}+\pi_{t}^{e}+\alpha_{2}\left(\pi_{t}-\pi_{t}^{T a r}\right)+\alpha_{3} \hat{y}_{t}\right]+\epsilon_{r s^{1 Y}, t}-\alpha_{4} \epsilon_{\pi^{T a r}, t}
\end{aligned}
$$

The two shocks in this equation are: $\epsilon_{r s^{1 Y}, t}$ which captures interest rate movements unexplained by all the elements in the reaction function; and $\epsilon_{\pi^{T a r}, t}$ which is designed to explain interest rate hikes due to the transition from a high to a low inflation regime that happened in the early 1980’s and 1990's.

The real one-year interest rate $\left(r r_{t}^{1 Y}\right)$ is defined as the difference between the nominal oneyear interest rate and expected inflation:

(6) $r r_{t}^{1 Y}=r s_{t}^{1 Y}-\pi_{t}^{e}$

Expected inflation is modeled as a linear combination of model-consistent expected inflation and lagged actual inflation:

$$
\text { (7) } \pi_{t}^{e}=\beta_{1} \pi_{t+1}+\left(1-\beta_{1}\right) \pi_{t-1}
$$

The equilibrium real interest rate $\left(\overline{r r}_{t}^{1 Y}\right)$ is modeled as a slow-moving autoregressive process (i.e., with high $\rho^{\overline{r r}^{1 Y}}$ ), which reverts to its long-run steady-state level $(\overline{r r} S S)$ and is also subject to a shock $\left(\epsilon_{\overline{r r}^{1 Y}, t}\right)$ :

(8) $r r_{t}^{1 Y}=\overline{r r}_{t}^{1 Y}+\widehat{r r}_{t}^{1 Y}$ 
(9) $\quad \overline{r r}_{t}^{1 Y}=\rho^{\overline{r r}^{1 Y}} \overline{r r}_{t-1}^{1 Y}+\left(1-\rho^{\overline{r r}^{1 Y}}\right) \overline{r r}^{S S}+\epsilon_{\overline{r r}^{1 Y}, t}$

The model allows the long-term bond yield to shed light on the estimates of the equilibrium real interest rate. Based on the expectations theory of the term structure, the interest rate on 10 -year government bonds is the sum of the average of expected future one-year interest rates, a term premium $\left(\sigma_{t}^{\text {Term }}\right)$, and a transitory shock to the 10 -year interest rate $\left(\epsilon_{r s^{10 Y}}\right)$ :

(10) $r s_{t}^{10 Y}=\frac{\sum_{i=t}^{t+9} r s_{i}^{1 Y}}{10}+\sigma_{t}^{T e r m}+\epsilon_{r s^{10 Y}}$

The term premium follows a slow autoregressive process (i.e., with high $\rho^{\sigma^{\text {Term }}}$ ) towards its long-run steady $\left(\sigma^{\text {Term,SS }}\right)$, subject to a shock $\left(\epsilon_{\sigma^{\text {term }}, t}\right)$ :

$$
\sigma_{t}^{\text {Term }}=\rho^{\sigma^{\text {Term }}} \sigma_{t-1}^{\text {Term }}+\left(1-\rho^{\sigma^{\text {Term }}}\right) \sigma^{\text {Term }, S S}+\epsilon_{\sigma^{\text {term }}, t}
$$

To the extent that forecasters see through the effects of temporary supply shocks on inflation and have a view about how output gaps affect inflation, information from Consensus forecasts helps us identify the structural shocks affecting the inflation equation. In addition, Consensus forecasts of future GDP growth can help us identify shocks that directly affect the output gap versus shocks that can have permanent and highly-persistent effects on the underlying trend growth rate of potential output. The Consensus forecasts are modeled as MPMOD's forecast for the CPI and GDP plus a measurement error. For example, Consensus forecasts for CPI inflation one year ahead would be equal to the structural model's forecast for CPI inflation plus a measurement error. The variances of the measurement errors are based on the historical forecast errors from Consensus forecasts.

The full model, including the new monetary block, is estimated with annual data covering the period from 1980 to 2016. We use annual instead of quarterly data to avoid problems with noise in high-frequency measures of inflation and also because Consensus Economics publishes annual forecasts for GDP growth and CPI inflation. We use 5-year-ahead CPI forecasts as a measure of the perceived long-term inflation target. This information helps to identify the underlying structural shocks of the model and changing perceptions of the inflation target in the monetary policy reaction function.

Figure 1 summarizes the MPMOD results for the United States from 1980 to 2026. For comparison, we have also included estimates of the output gap, potential growth, and the natural rate of unemployment (NAIRU) from the Congressional Budget Office (CBO) ${ }^{4}$. The $\mathrm{CBO}$, using the framework of a Solow growth model, disaggregates output into five sectors:

\footnotetext{
${ }^{4}$ Data are from Federal Reserve Bank of St. Louis, FRED Economic Data, updated on August 8, 2017.
} 
nonfarm business, households and nonprofit institutions, government, farm, and housing (see CBO papers, 2001, 2014). The output gaps from the MPMOD and the CBO are highly correlated, but the MPMOD’s estimates are larger, on average, by about 0.8 percentage points. The periods of excess demand from MPMOD typically preceded increases in inflation and hikes in the monetary policy interest rate. The two models' estimates of potential growth are also highly correlated - both move partly with trends in actual growth, with the CBO's estimates implying higher potential growth in the early 1980s and late 1990s.

\section{Figure 1. Comparison of MPMOD Estimates with CBO Estimates}

\section{Panel 1a. Output Gap (percent of potential)}

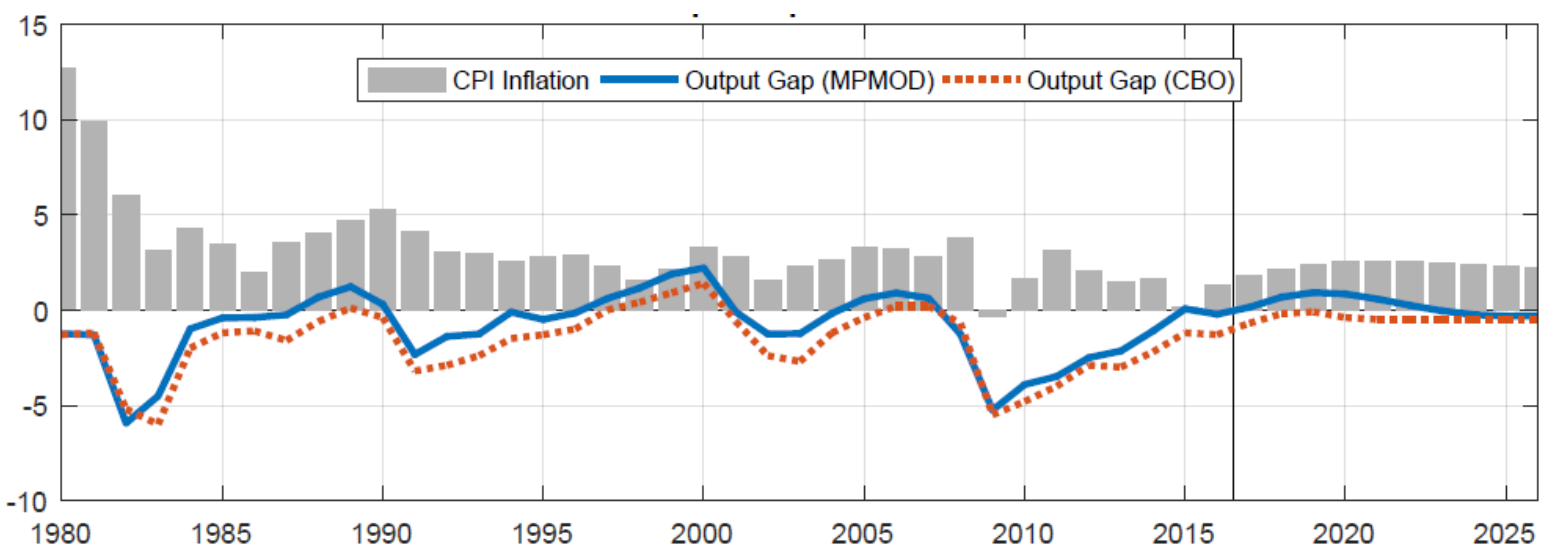

Panel 1b. Potential GDP Growth (percent)

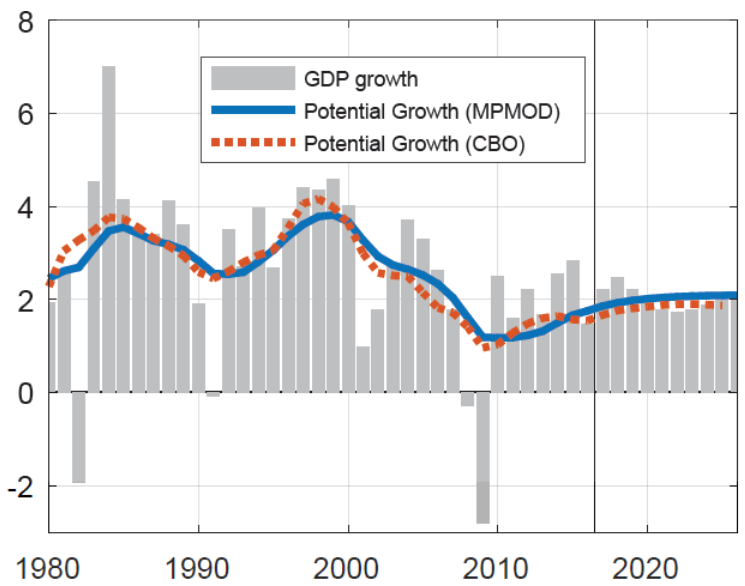

Source: Authors' estimates, CBO.
Panel 1c. Natural Rate of Unemployment (percent)

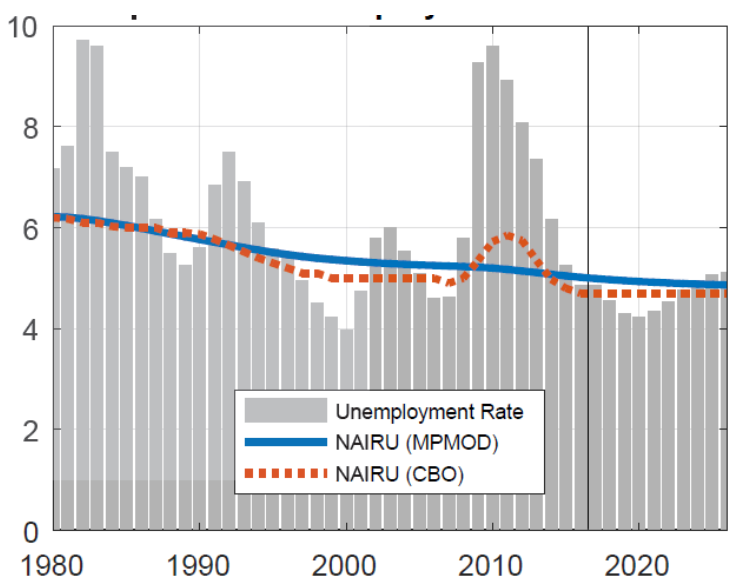

Estimates of the NAIRU from both models trend down, with the CBO's estimates being slightly lower at the end of the sample. Note that the CBO's estimates include a temporary increase in the NAIRU during the global financial crisis. These small differences in the 
NAIRU estimates do not materially affect recent potential growth or gaps. To see this, Figure 2 presents estimates of the MPMOD output gap and potential growth, taking the CBO estimates of the NAIRU as an observable variable. The results are almost unchanged.

Figure 2. Sensitivity Analysis

Panel 2a. Output Gap (percent of potential)

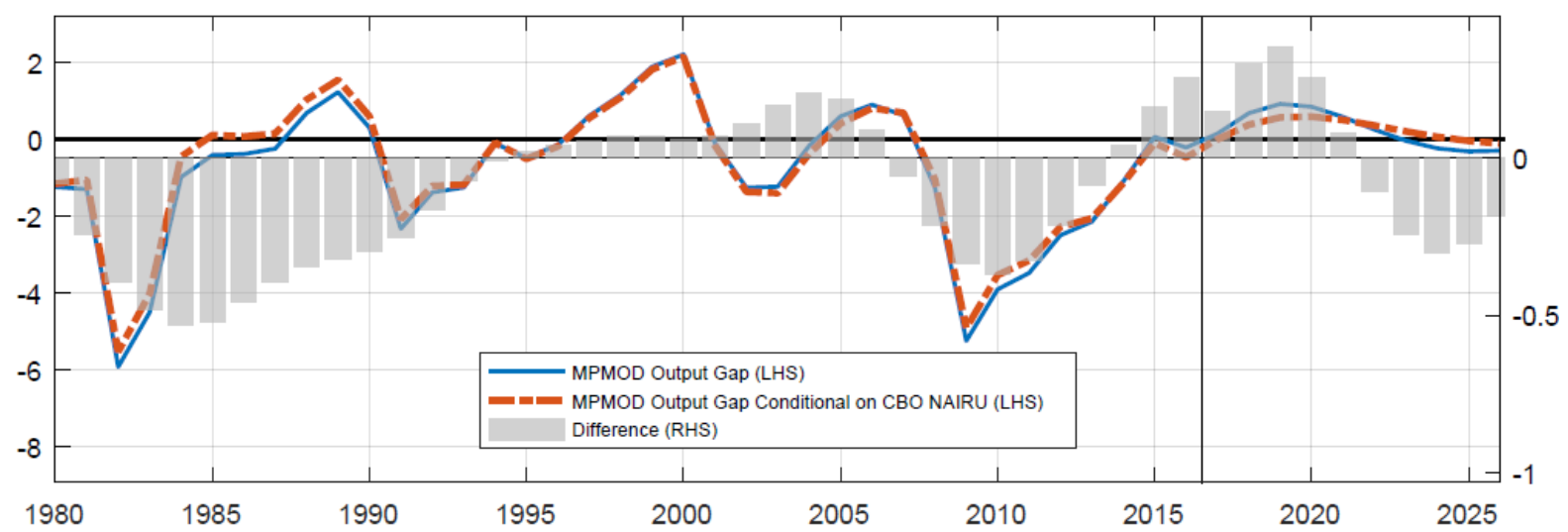

Panel 2b. Potential GDP Growth (percent)

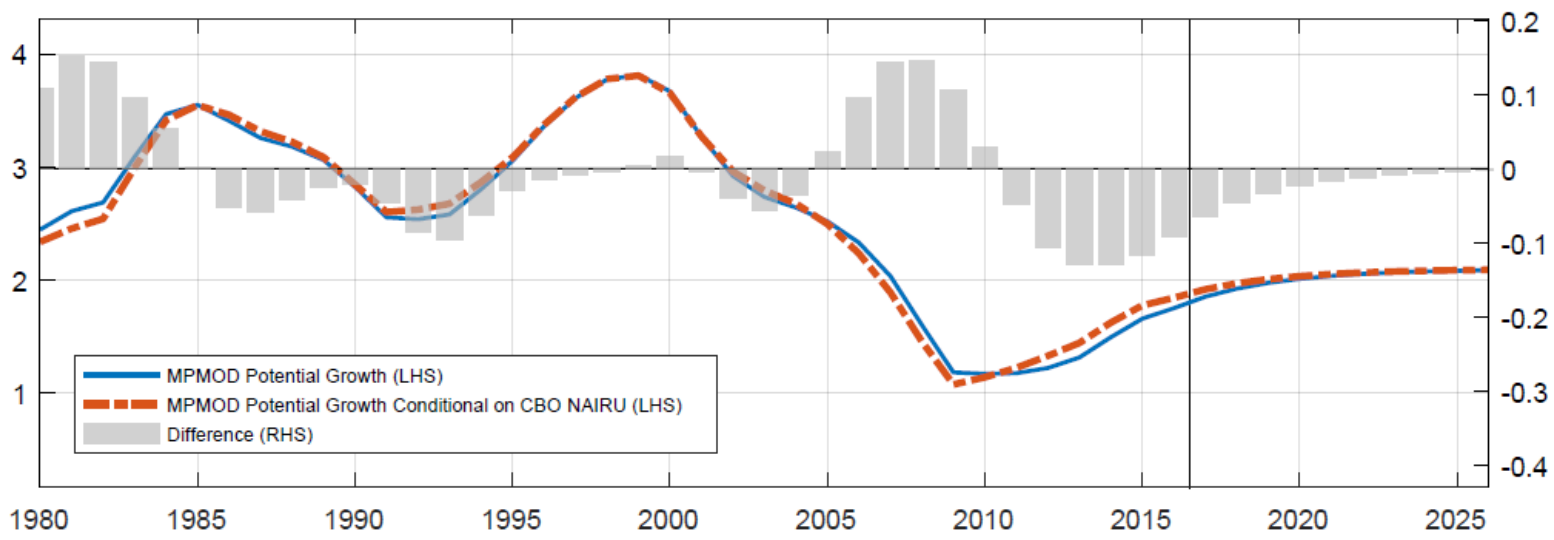

Source: Authors' estimates, CBO.

The MPMOD multivariate filter produces more robust real-time estimates of potential output and output gap than a univariate HP filter does. Figure 3, Panel 3a, 3b, and 3c compare realtime estimates produced by MPMOD, an HP filter with $\Lambda=6.25^{5}$, and MPMOD without the monetary policy block. Each red circle in the figure is the estimate of potential output by the relevant model using only data up to that point. By contrast, the solid black line uses the full data set to generate ex-post estimates by each of the three models. The grey bars are the revisions (differences) between the real-time and ex-post estimates: a smaller bar implies a smaller revision between the real-time and ex-post estimates. The real-time MPMOD

${ }^{5}$ The smoothing parameter of 6.25 in annual data is equivalent to using 1600 for quarterly data. 
estimates track the corresponding ex-post estimates quite closely, outperforming the HP filter. Moreover, MPMOD with the monetary policy block has generally smaller revisions compared to MPMOD without the monetary policy block.

Panel 3d and 3e show the real-time forecasts of MPMOD and the HP filter. Each colored circle is the real-time estimate (the same as the circles in Panel 3a, 3b and 3c), and the colored lines are the real-time forecasts at each time period (i.e., using data only up to that time).

\section{Figure 3. Real-time Estimates and Rolling Forecasts}

Panel 3a. MPMOD Real-time Estimates

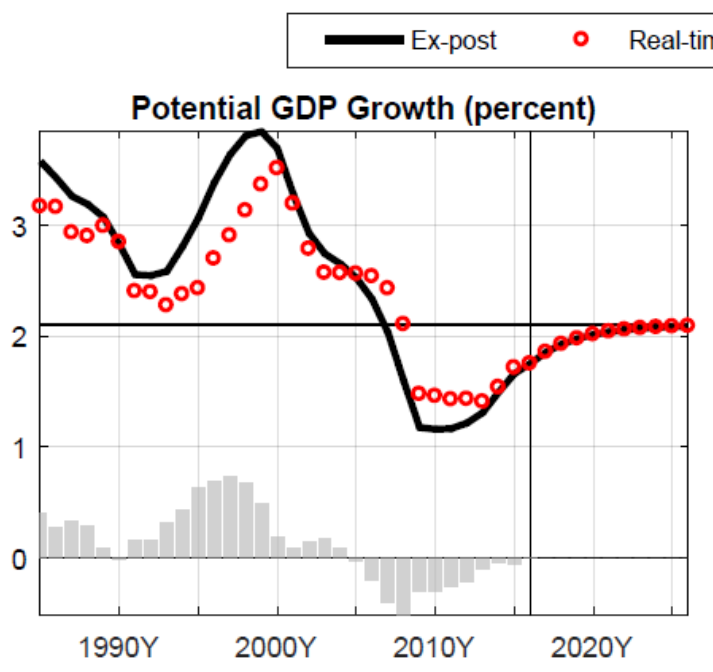

Revision (percentage points)

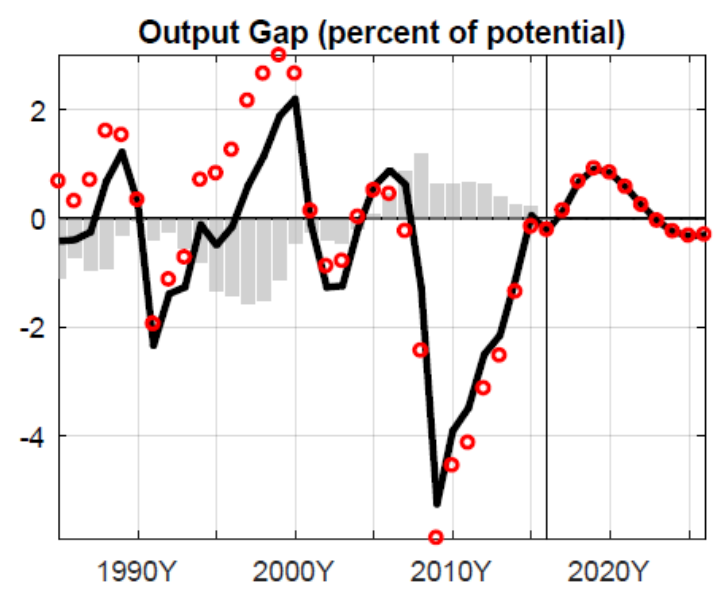

Panel 3b. HP Filter Real-time Estimates

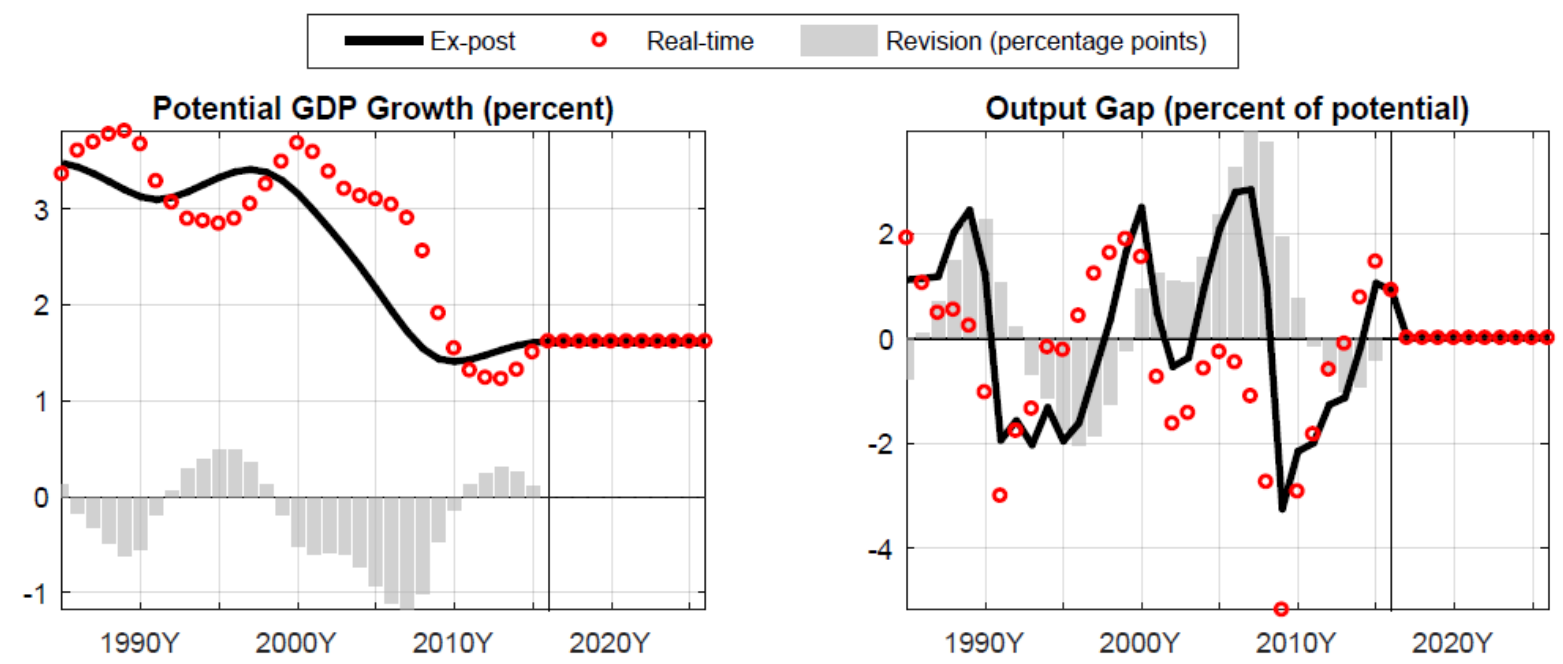


Panel 3c. MPMOD without Monetary Policy Block Real-Time Estimates
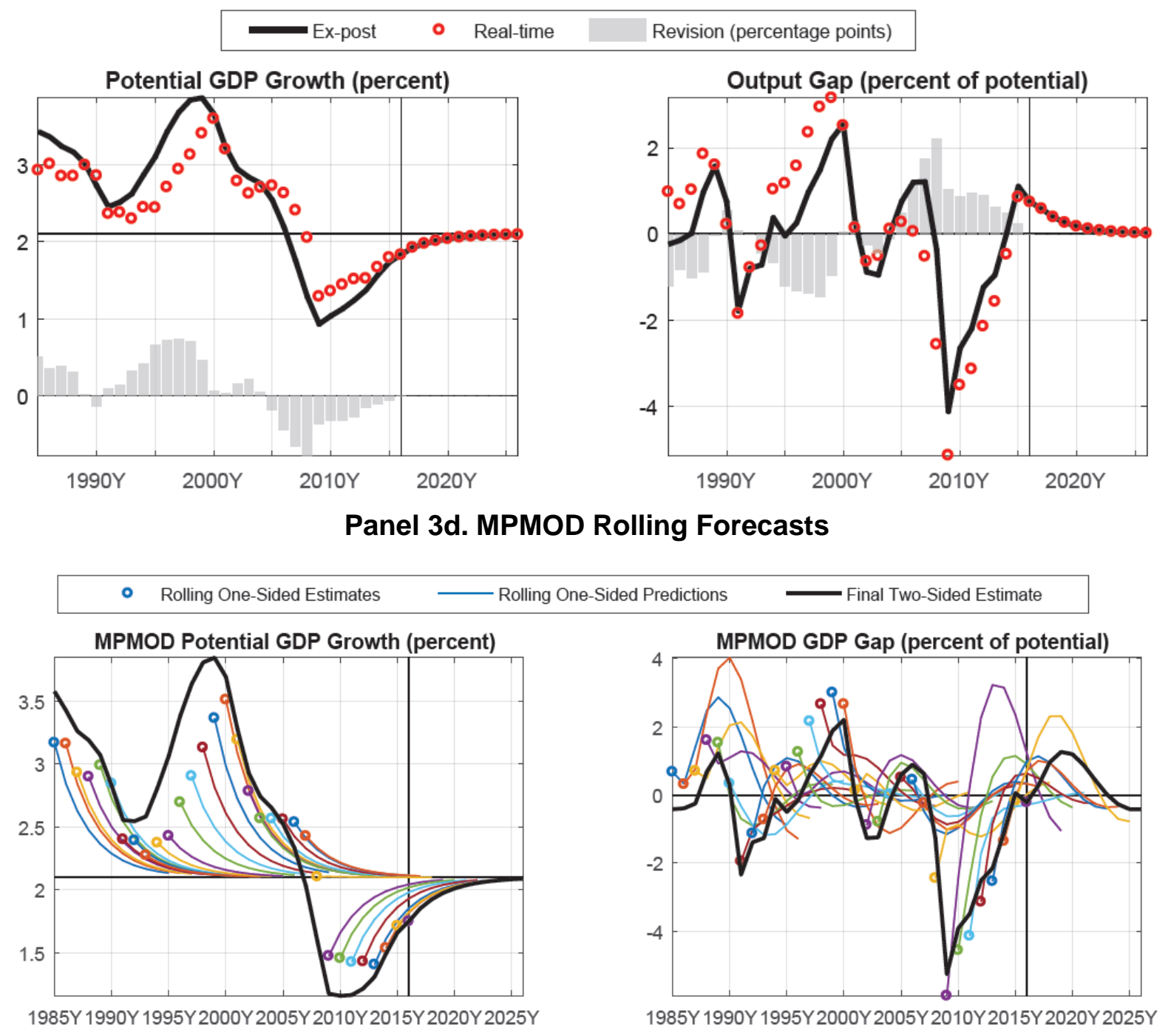


\section{Panel 3e. HP Filter Rolling Forecasts}

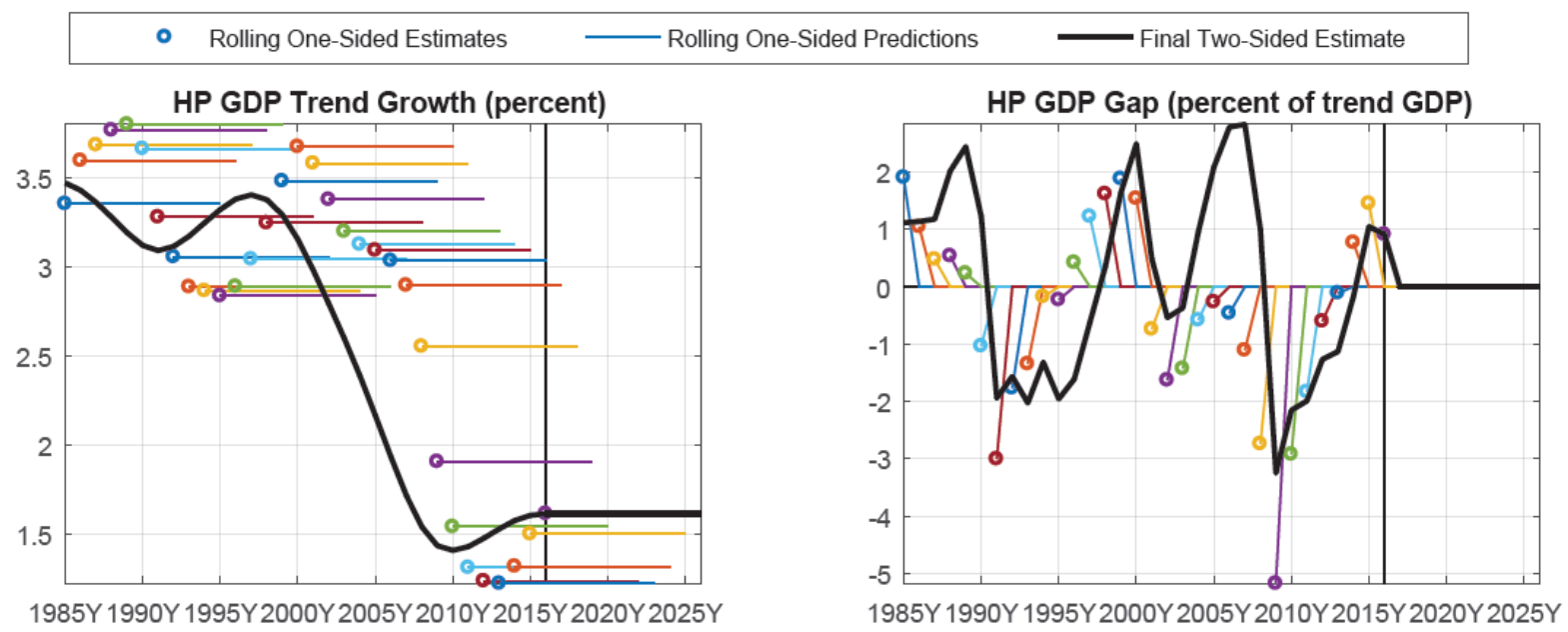

Source: Authors' estimates.

Figure 3, Panel 3e illustrates the so-called end-point problem that plagues the HP filter, which essentially extrapolates its last (end point) estimate. Some insight into this behavior can be gleaned by examining the HP filter in a state space representation applied to the log of GDP:

$$
\begin{array}{ll}
y_{t}=\bar{y}_{t}+\hat{y}_{t} & \\
\Delta \bar{y}_{t}-\Delta \bar{y}_{t-1}=\varepsilon_{t}^{\bar{y}}, & \varepsilon_{t}^{\bar{y}} \sim i i d\left(0, \sigma_{\varepsilon}^{2}\right) \\
\hat{y}_{t}=\varepsilon_{t}^{\hat{y}}, & \varepsilon_{t}^{\hat{y}} \sim i i d\left(0, \sigma_{\varepsilon \hat{y}}^{2}\right) \\
\frac{\sigma_{\varepsilon}^{2}}{\sigma_{\varepsilon \hat{y}}^{2}}=\Lambda &
\end{array}
$$

The HP filter decomposes the actual GDP level into trend and gap components (equation 12). The first difference of the trend GDP, its growth rate, is assumed to be a random walk (equation 13), while the GDP gap is assumed to be white noise (equation 14). The smoothness of the trend is pinned down by explicitly specifying the signal-to-noise ratio $(\Lambda$, equation 15). From this, it is clear that whenever there is a shift in output growth, the HP filter assumes it is permanent and forecasts accordingly. Unless growth is stable, or the practitioner intervenes to adjust the results in an ad hoc way, this leads to large revisions. ${ }^{6}$

\footnotetext{
${ }^{6}$ For a discussion of the historical revisions to real-time output gaps published by the OECD and other institutions during the global financial crisis see Turner and others (2016) and Borio, Disyata and Juselius (2016).
} 
Figure 4 compares the estimates of the output gap and potential growth of MPMOD with the same model but without the monetary policy block or the associated interest rates and term premium. MPMOD estimates somewhat deeper and prolonged recessions, especially after the global financial crisis. The simultaneous estimation procedure implies that the reaction function and term structure equation have information about the output gap. Thus, the extraordinary easing of policy is explained by the need to fight an extraordinarily large (estimated) output gap.

\section{Figure 4. Comparison of Multivariate Filter Results with and without the Monetary Policy Block}

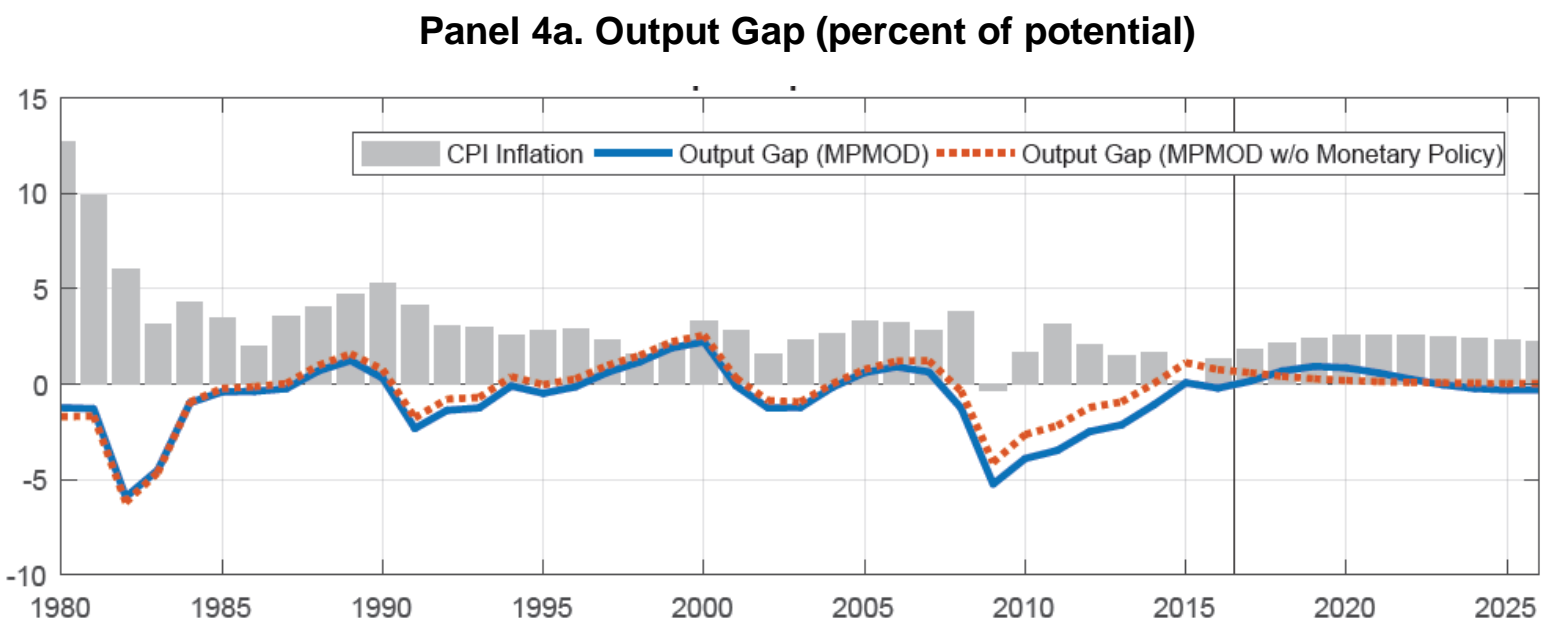

Panel 4b. Potential GDP Growth (percent)

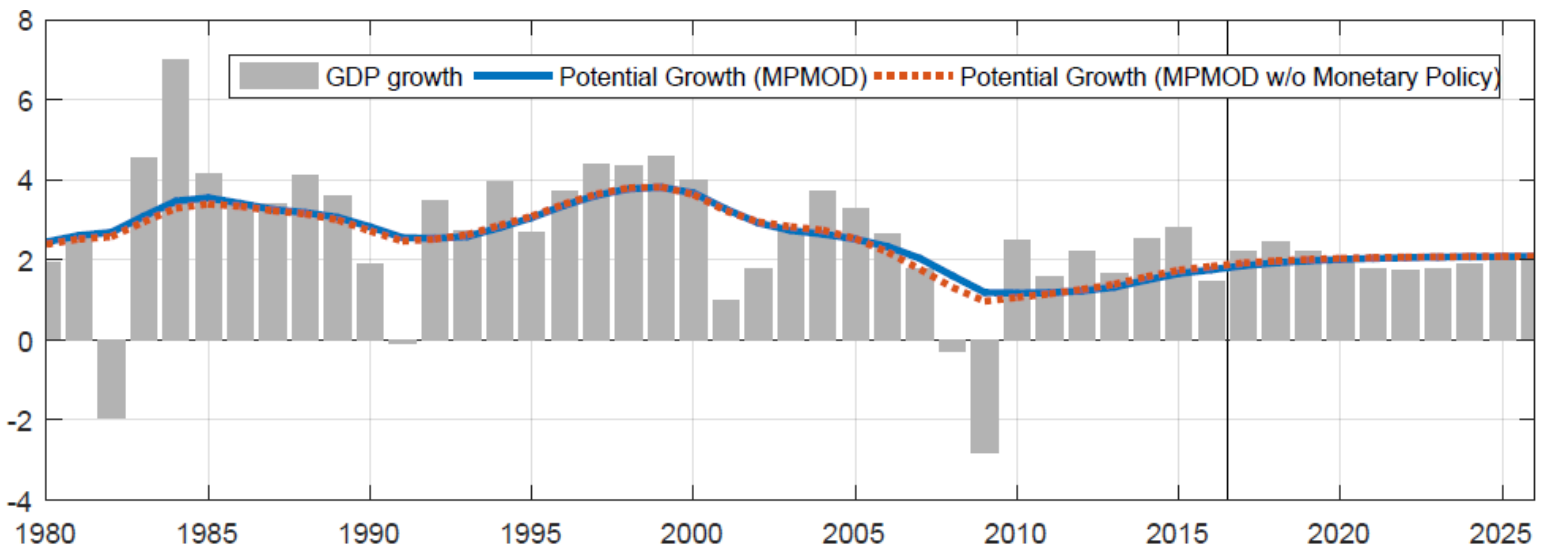

Source: Authors' estimates. 


\section{Properties of MPMOD}

Figure 5 summarizes the MPMOD detailed results for 1980 to 2026. The implicit inflation target is based on inflation expectations 5-year-ahead from Consensus Economics, available from 1989 to 2017. For 1980, the 5-year-ahead CBO inflation forecast is used. The values from 1981 to 1988 are treated as unobservable and computed from the Kalman filter. The perceived inflation target decreased in the 1980's and 1990's, reflecting the Volker disinflation.

Before the global financial crisis, the U.S. economy was operating above potential, pushing inflation up. As a result, monetary policy tightened moderately. The global financial crisis that started in late 2008 pushed U.S. economy into a deep recession. The unemployment rate rose sharply and capacity utilization in the manufacturing sector dropped. In response, monetary (and fiscal) policy became markedly expansionary. ${ }^{7}$

After the great recession, GDP grew faster than potential and the (negative) output gap narrowed correspondingly. However, the inflation rate has remained below target. Under such circumstances, monetary policy was correctly accommodative. MPMOD estimates indicate that the U.S. output gap is now almost closed and the unemployment rate is almost at the NAIRU. The model suggests that for the next few years the output gap will go positive and the unemployment rate will fall below the NAIRU.

\section{Figure 5. MPMOD Detailed Results}

\section{Panel 5a. Short-Term Interest Rate and} Inflation (percent)

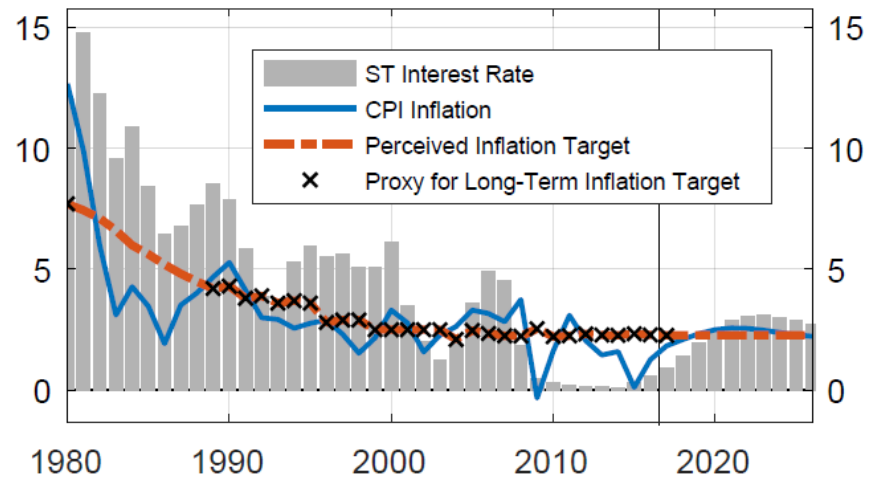

Panel 5b. Output Gap (percent of potential) and Inflation (percent)

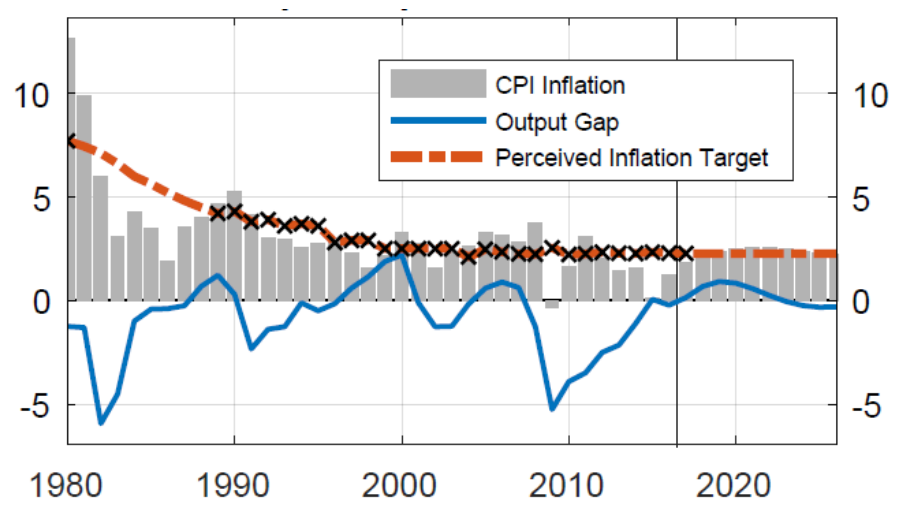

\footnotetext{
${ }^{7}$ For a discussion of the role of fiscal policy see Freedman and others (2009).
} 
Panel 5c. Short-Term Interest Rate (percent)

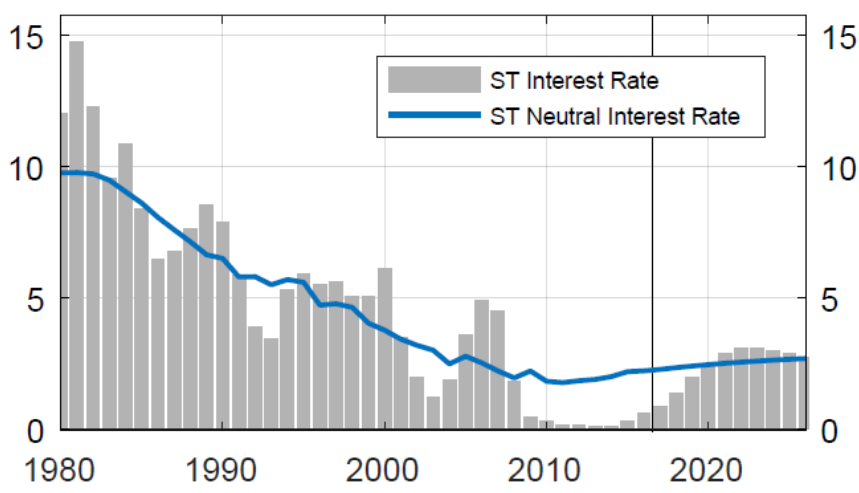

Panel 5e. Long-Term Interest Rate, Expected Short-Term Interest Rate, and Term Premium (percent)

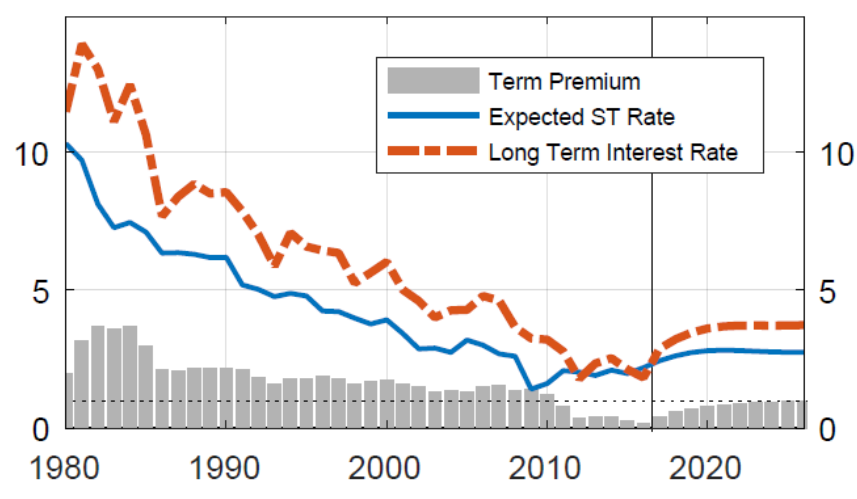

Panel 5g. Potential GDP Growth (percent)

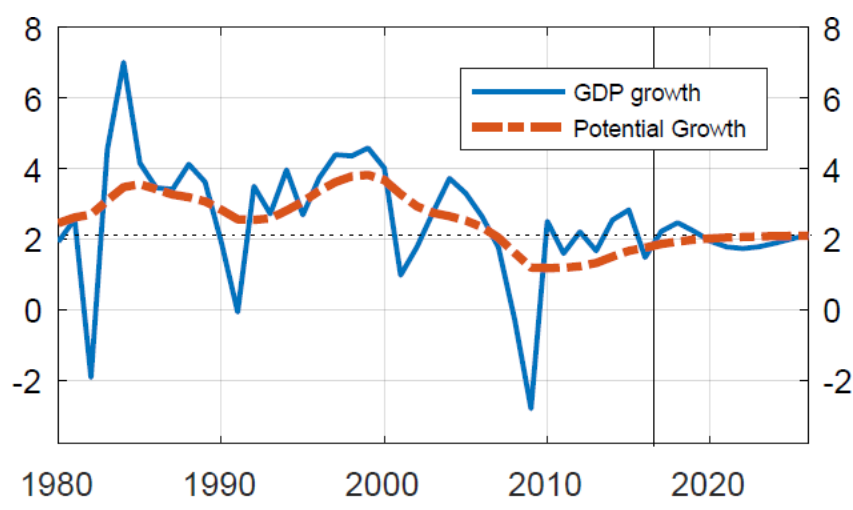

Source: Authors' estimates.
Panel 5d. Real Interest Rate (percent)

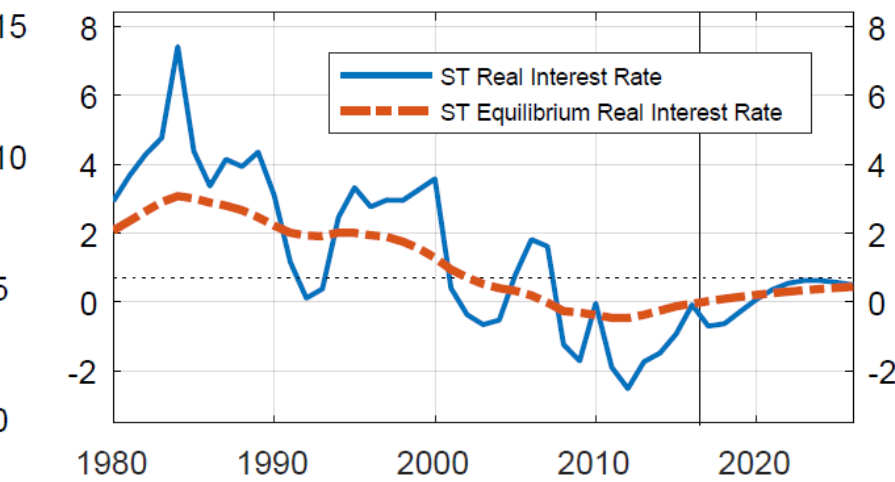

Panel 5f. Natural Rate of Unemployment (percent)

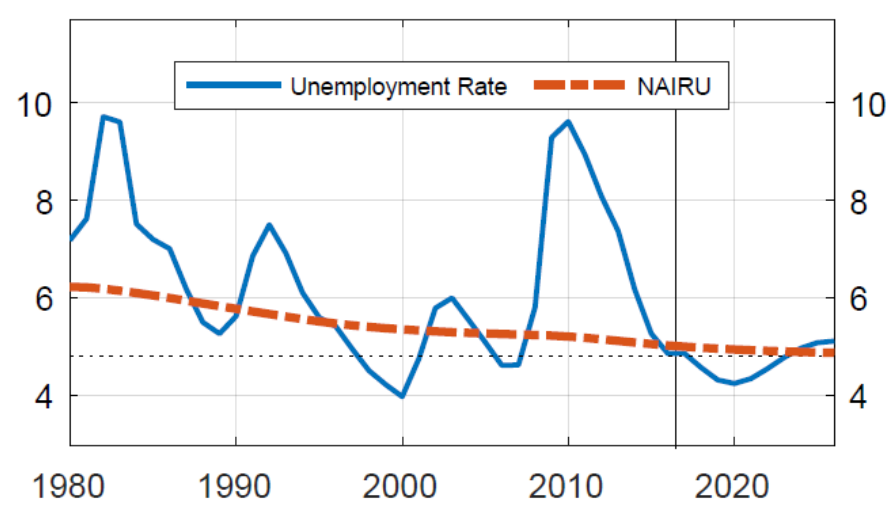

Panel 5h. The Output Gap and Capacity Utilization Gap (percent of potential)

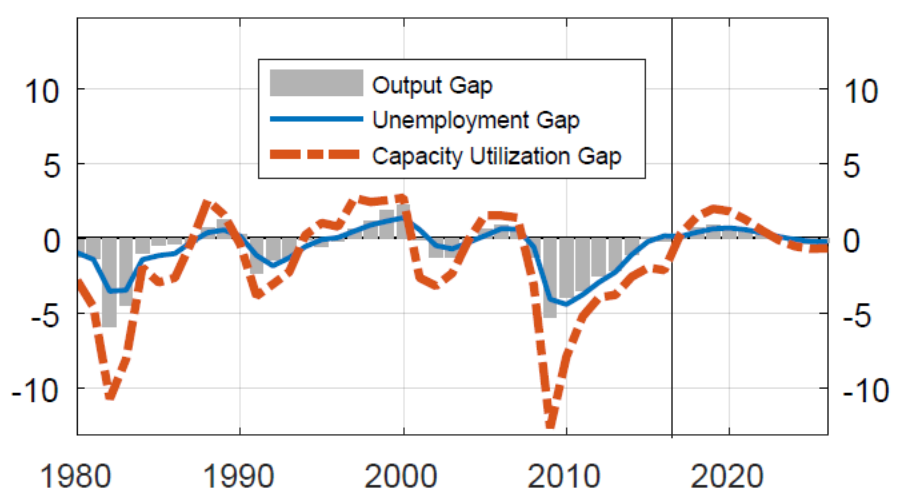




\section{IMPULSE RESPONSE ANALYSIS}

Figures 6, 7, 8, and 9 depict impulse responses to the shocks on: the output gap, the level of potential, the growth rate of potential, and the perceived inflation target.

In Figure 6, we consider a one-standard-deviation positive demand shock to output $\left(\epsilon_{y, t}\right)$, which causes output to temporarily deviate from its steady-state level. There is by construction no change in potential output. The positive output gap pushes inflation up by nearly 0.2 percentage points. In response to this shock, monetary policy tightens and the short-term interest rate rises by more than 0.3 percentage points. This is transmitted to the long-term interest rate through expectations. The long-term interest rate goes up by 0.1 percentage points.

Figure 7 illustrates a one standard deviation positive shock to the level of potential output. The potential output level shock pushes demand up as economic agents start to consume and invest more, but initially supply rises more than demand and output gap becomes negative. In the Phillips curve equation, the increase in productivity lowers marginal costs, which also pushes inflation down. In response, monetary policy loosens. The short-term interest rate decreases by 0.04 percentage points.

Figure 8 illustrates a shock to the growth rate of potential output $\left(\epsilon_{g_{\bar{y}}, t}\right)$, which causes an increase in potential output growth for several periods until the impact fades out and growth returns to its (unchanged) steady-state. As in the previous shock, consumers and firms recognize that their permanent incomes are higher and so increase consumption and investment. Unlike the previous shock, however, potential output does not rise immediately and a positive output gap opens up. Inflation rises and monetary policy tightens.

Finally, figure 9 illustrates a negative shock to the inflation target by one percentage point, which causes monetary policy to tighten. Tighter monetary policy reduces real output temporarily, but it eventually returns to (unchanged) potential. By that point, inflation has fallen to the new target. 
Figure 6. Impulse Response for a 1-Standard-Deviation Positive Shock to the Output Gap
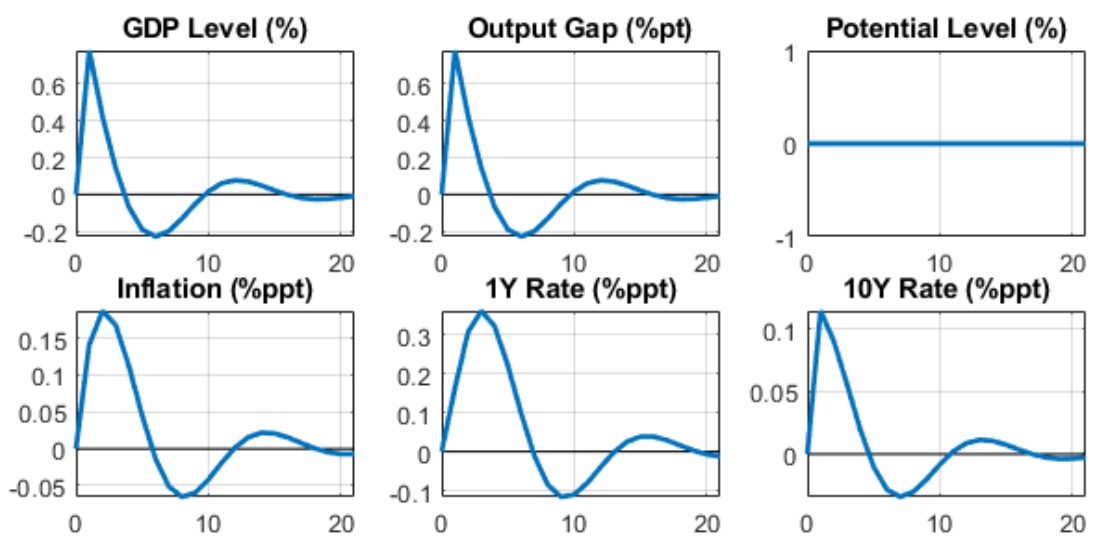

Cumulative Output Gap (\%pt)
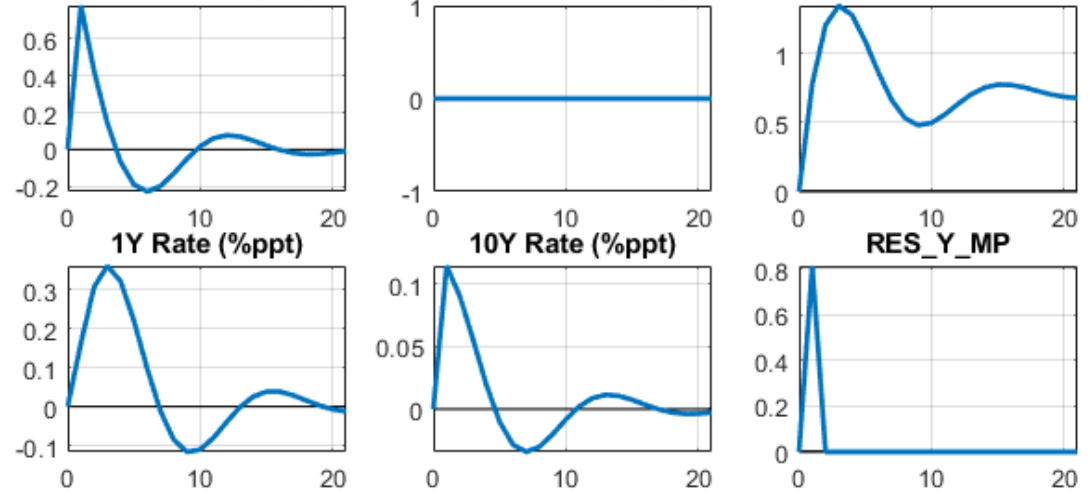

Source: Authors' estimates.

Figure 7. Impulse Response for a 1-Standard-Deviation Positive Shock to the Level of Potential Output
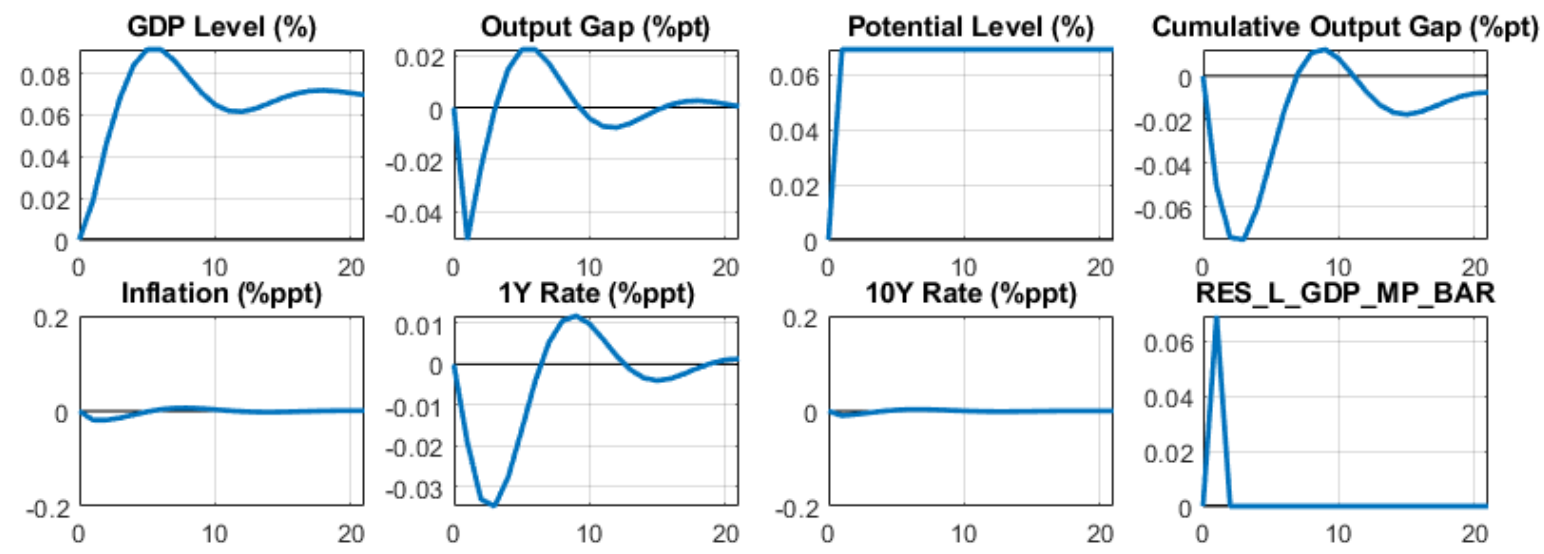

Source: Author's estimates. 
Figure 8. Impulse Response for a 1-Standard-Deviation Positive Shock to the Growth Rate of Potential Output
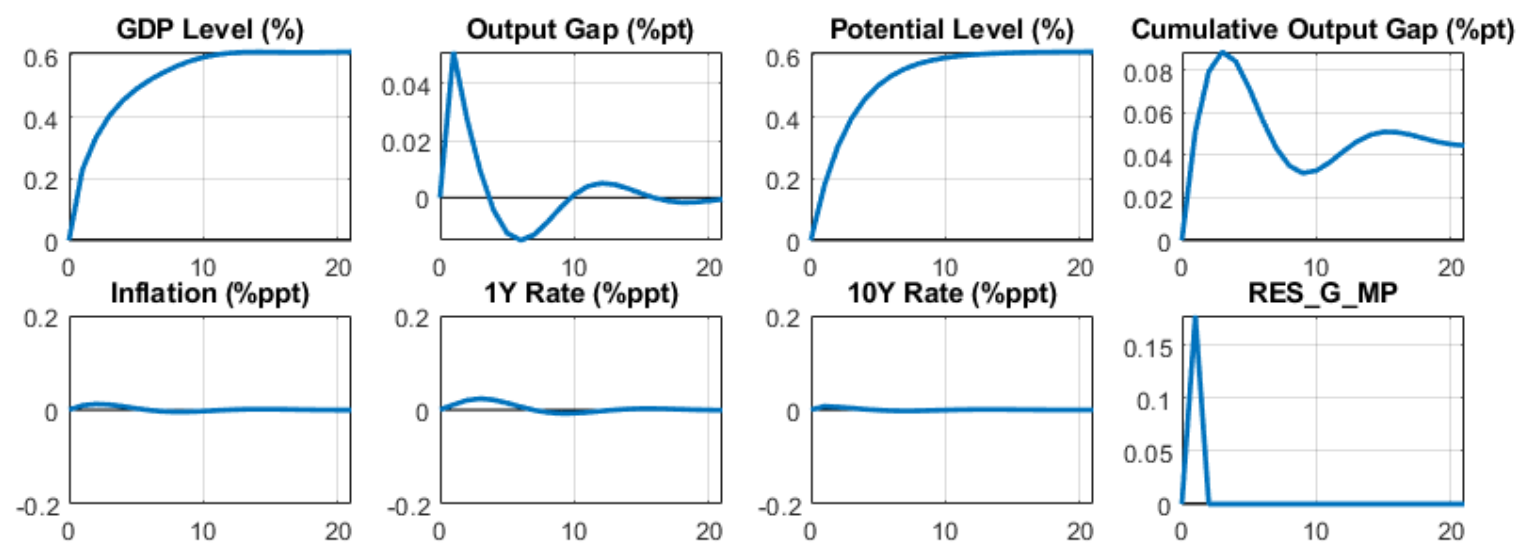

Source: Authors' estimates.

Figure 9. Impulse Response for a 1-Standard-Deviation Negative Shock to the Inflation Target
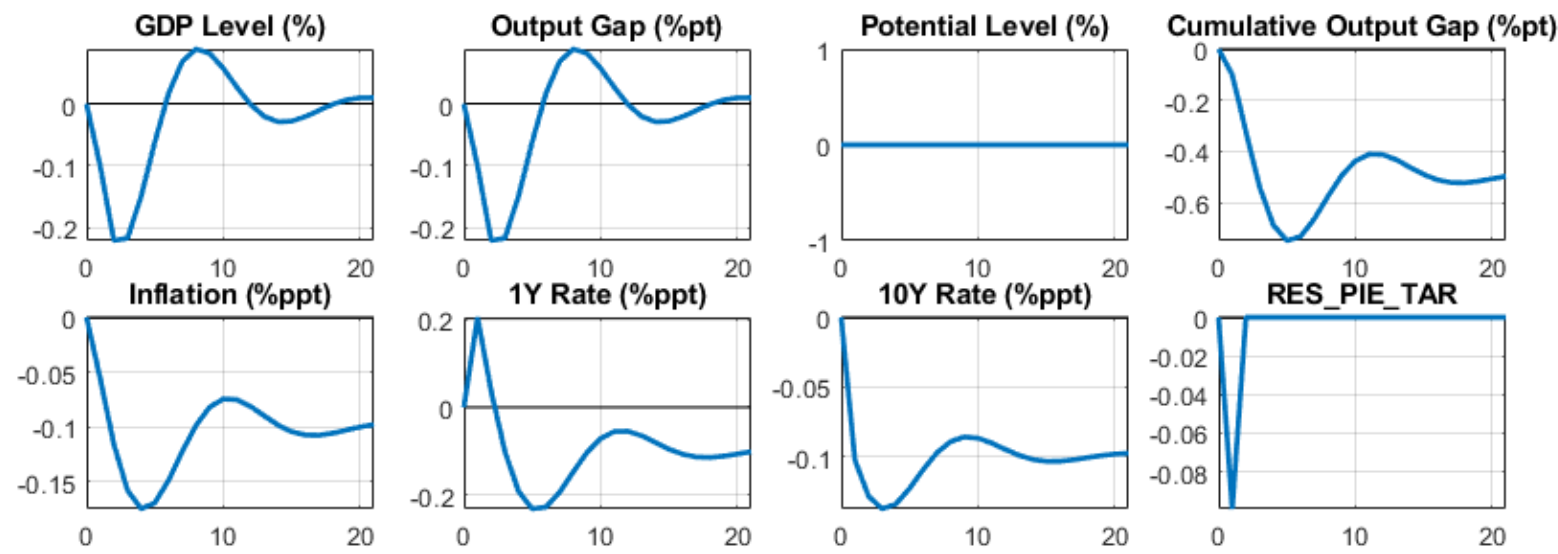

Source: Authors' estimates.

\section{Concluding Remarks}

This paper extends the multivariate filter approach for measuring potential output developed by Alichi and others (2017) by adding a monetary policy block (MPMOD). This addition provides more structural description of dynamics of the output gap and allows monetary policy to interact with demand and supply shocks. The addition of the monetary block generates estimates of the post-global-financial-crisis recession that are deeper and more prolonged. As with other multivariate filters, MPMOD produces more reliable real-time 
estimates than an HP filter, and the addition of the monetary policy block further improves the reliability of the structural multivariate filter.

Additional extensions of the multivariate filter model are underway. Alichi and others (2018a) add a production function and disaggregate full-employment labor inputs into the participation rate, the NAIRU, and labor force population. Alichi and others (2018b) extend the basic model to allow for partial hysteresis in the labor market. Finally, Alichi and others (2018c) show how the model can be extended to incorporate information about the financial cycle. 


\section{REFERENCES}

Alichi, A., 2015, “A New Methodology for Estimating the Output Gap in the United States,” IMF Working Paper No. 15/144.

Alichi, A., O. Bizimana, S. Domit, E. Fernández-Corugedo, D. Laxton, K. Tanyeri, H. Wang, and F. Zhang, 2015, "Multivariate Filter Estimation of Potential Output for the Euro Area and the United States,” IMF Working Paper No. 15/253.

Alichi, A., O. Bizimana, D. Laxton, K. Tanyeri, H. Wang, J. Yao, and F. Zhang, 2017, "Multivariate Filter Estimation of Potential Output for the United States," IMF Working Paper No. 17/106.

Alichi, A., R. Al-Mashat, H. Avetisyan, J. Benes, O. Bizimana, A. Butavyan, R. Ford, N. Ghazaryan, V. Grigoryan, M. Harutyunyan, A. Hovhannisyan, E. Hovhannisyan, H. Karapetyan, M. Kharaishvili, D. Laxton, A. Liqokeli, K. Matikyan, G. Minasyan, S. Mkhatrishvili, A. Nurbekyan, A. Orlov, B. Pashinyan, G. Petrosyan, Y. Rezepina, A. Shirkhanyan, T. Sopromadze, L. Torosyan, E. Vardanyan, H. Wang, and J. Yao, 2018a, "Estimating Potential Output Using a Multivariate Filter Augmented with a Production Function,” IMF Working Paper (forthcoming).

Alichi, A., R. Al-Mashat, H. Avetisyan, J. Benes, O. Bizimana, A. Butavyan, R. Ford, N. Ghazaryan, V. Grigoryan, M. Harutyunyan, A. Hovhannisyan, E. Hovhannisyan, H. Karapetyan, M. Kharaishvili, D. Laxton, A. Liqokeli, K. Matikyan, G. Minasyan, S. Mkhatrishvili, A. Nurbekyan, A. Orlov, B. Pashinyan, G. Petrosyan, Y. Rezepina, A. Shirkhanyan, T. Sopromadze, L. Torosyan, E. Vardanyan, H. Wang, and J. Yao, 2018b, "Multivariate Filter Estimation of Potential Output for the United States: An Extension with Labor Market Hysteresis,” IMF Working Paper (forthcoming).

Alichi, A., R. Al-Mashat, H. Avetisyan, J. Benes, O. Bizimana, A. Butavyan, R. Ford, N. Ghazaryan, V. Grigoryan, M. Harutyunyan, A. Hovhannisyan, E. Hovhannisyan, H. Karapetyan, M. Kharaishvili, D. Laxton, A. Liqokeli, K. Matikyan, G. Minasyan, S. Mkhatrishvili, A. Nurbekyan, A. Orlov, B. Pashinyan, G. Petrosyan, Y. Rezepina, A. Shirkhanyan, T. Sopromadze, L. Torosyan, E. Vardanyan, H. Wang, and J. Yao, 2018c, "Mind the Gaps! Incorporating Information about the Financial Cycle into Medium-Term Projections of Potential Output,” IMF Working Paper (forthcoming).

Alichi, A., H. Chen, K. Clinton, C. Freedman, M.J. Johnson, O. Kamenik, T. Kisinbay, and D. Laxton, 2009, “Inflation Targeting Under Imperfect Policy Credibility,” IMF Working Paper No. 09/94. 
Argov, E., N. Epstein, P. Karam, D. Laxton, and D. Rose, 2007, "Endogenous Monetary Policy Credibility in a Small Structural Model of Israel,” IMF Working Paper No. 07/207.

Benes, J., K. Clinton, R. Garcia-Saltos, M. Johnson, D. Laxton, P. Manchev, and T. Matheson, 2010, “Estimating Potential Output with a Multivariate Filter,” IMF Working Paper No. 10/285.

Blagrave, P., R. Garcia-Saltos, D. Laxton, and F. Zhang, 2015 “A Simple Multivariate Filter for Estimating Potential Output,” IMF Working Paper No. 15/79.

Borio, C., Disyatat, P. and Juselius, M, 2016, “Rethinking Potential Output: Embedding Information about the Financial Cycle,” Oxford Economic Papers 69.3 (2016): 655677.

CBO, 2011, “CBO’s Method for Estimating Potential Output: An Update.”

CBO, 2014, “Revisions to CBO’s Projection of Potential Output Since 2007.”

Clark, P., D. Laxton, and D. Rose, 2001, “An Evaluation of Alternative Monetary Policy Rules in a Model with Capacity Constraints,” Journal of Money Credit and Banking, Vol. 33, No. 1 (February), pp. 42-64.

Clark, P., D. Laxton, and D. Rose, 1995, “Capacity Constraints, Inflation and the Transmission Mechanism: Forward-Looking Versus Myopic Policy Rules,” IMF Working Paper No. 95/75.

Clinton, K., Freedman, C. Juillard, M. Kamenik, O. Laxton, D. and Wang, H, 2015, "Inflation-Forecast Targeting: Applying the Principle of Transparency," IMF Working Paper No. 15/132.

Debelle, G., and D. Laxton, 1997, "Is the Phillips Curve Really a Curve? Some Evidence for Canada, The United Kingdom and the United States,” Staff Papers, International Monetary Fund, Vol. 44, No. 2, June, pp. 249-82.

Freedman, C., M. Kumhof, D. Laxton, D. Muir, and S. Mursula, 2009, “Fiscal Stimulus to the Rescue? Short-Run Benefits and Potential Long-Run Costs of Fiscal Deficits., IMF Working Paper No. 255, November.

Hodrick, R.J., and E.C. Prescott, 1997, "Post-War U.S. Business Cycles: An Empirical Investigation,” Journal of Money, Credit and Banking, Vol. 29(1), pp. 1-16 
Isard, P., D. Laxton, and A. Eliasson, 1999, "Simple Monetary Policy Rules Under Model Uncertainty,” International Tax and Public Finance, Vol. 6, pp. 537-577.

Juillard, M., O. Kamenik, M. Kumhof, and D. Laxton, 2007, "Measures of Potential Output from an Estimated DSGE Model of the United States,” paper presented at a workshop on Issues in Measuring Potential Output, Ankara Turkey, January 16.

Laxton, D., N. Ricketts, and D. Rose, 1993, "Uncertainty, Learning and Policy Credibility, Economic Behavior and Policy Choice Under Price Stability,” Proceedings of a Conference held at the Bank of Canada, 30-31 October.

Laxton, D., D. Rose, and R. Tetlow, 1993a, "Problems in Identifying Nonlinear Phillips Curves: Some Further Consequences of Mismeasuring Potential Output,” Bank of Canada Working Paper No. 93/6.

Laxton, D., D. Rose, and R. Tetlow, 1993b, Monetary Policy, "Uncertainty and the Presumption of Linearity,” Bank of Canada Technical Report No. 63.

Laxton, D. and R. Tetlow, 1992, "A Simple Multivariate Filter for the Measurement of Potential Output,” Technical Report No. 59 (Ottawa: Bank of Canada).

Okun, A.M., 1962, "Potential GNP: Its Measurement and Significance,” in Proceedings of the Business and Economic Statistics Section, pp. 98-104 (Washington: American Statistical Association).

Turner, D., M. Cavalleri, Y. Guillemette, A. Kopoin, P. Ollivaud, E. Rusticelli, 2016, “An investigation into improving the real-time reliability of OECD output gap estimates", OECD Economics Department Working Papers, No. 1294 


\section{APPENDIX}

\section{A. MPMOD Equations}

The core data for the model are: GDP, CPI, the unemployment rate, the capacity utilization rate in the manufacturing sector, and short- and long-term interest rates. We measure the data at annual frequency to reduce the noise in the quarterly data. In addition, we use data from Consensus forecasts of annual CPI inflation and real GDP growth to help better identify supply and demand shocks and deal with end-point problems. In this section, we present the equations of the model. Parameter values and the standard errors of shock terms for these equations are estimated using Bayesian estimation techniques and are provided (see Table B1 and B2).

The output gap is defined as the deviation of real GDP, in log terms $\left(y_{t}\right)$, from its potential level $\left(\bar{y}_{t}\right)$ :

$$
\hat{y}_{t}=y_{t}-\bar{y}_{t}
$$

The stochastic process for output (real GDP) is defined by three equations, (17)-(19), and three types of shocks:

$$
\begin{aligned}
& \bar{y}_{t}=\bar{y}_{t-1}+g_{\bar{y}, t}+\epsilon_{\bar{y}, t} \\
& g_{\bar{y}, t}=\left(1-\rho_{g_{\bar{y}}}\right) g_{\bar{y}, t-1}+\rho_{g_{\bar{y}}} g_{\bar{y}}^{s s}+\epsilon_{g_{\bar{y}}, t} \\
& \hat{y}_{t}=\phi_{1} \hat{y}_{t-1}-\phi_{2} \widehat{r r}_{t}^{1 Y}-\phi_{3} \widehat{r r}_{t-1}^{1 Y}+\phi_{4} \epsilon_{g_{\bar{y}}, t}-\phi_{5} \epsilon_{\bar{y}, t}+\epsilon_{\hat{y}, t} \\
& g_{t}=y_{t}-y_{t-1} \\
& g_{\bar{y}, t}=\bar{y}_{t}-\bar{y}_{t-1}
\end{aligned}
$$

The level of potential output $\left(\bar{y}_{t}\right)$ evolves according to trend potential growth $\left(g_{\bar{y}, t}\right)$ and a level-shock term $\left(\epsilon_{\bar{y}, t}\right)$. Potential growth is also subject to shocks $\left(\epsilon_{g_{\bar{y}}, t}\right)$, whose impact fades gradually according to the parameter $\rho_{g_{\bar{y}}}$ (a lower value means a slower adjustment back to the steady-state growth rate following a shock). Finally, the output gap $\left(\hat{y}_{t}\right)$ is a function of contemporaneous and lagged values of the one-year real interest rate gap $\left(\widehat{r r}_{t}^{1 Y}\right)$ which is the deviation of short-term interest rate from its equilibrium level. The output gap equation also incorporates shocks to potential growth $\left(\epsilon_{g_{\bar{y}}, t}\right)$ and shocks to the level of potential output $\left(\epsilon_{\bar{y}, t}\right)$. It is also subject to shocks $\left(\epsilon_{\hat{y}, t}\right)$, which are interpreted as demand shocks (raise 
demand). A stylized representation of how GDP responds to each shock term is expressed graphically in Figure A1:

Figure A1. Shocks to the Level and Growth Rate of Potential Output, and to the Output Gap

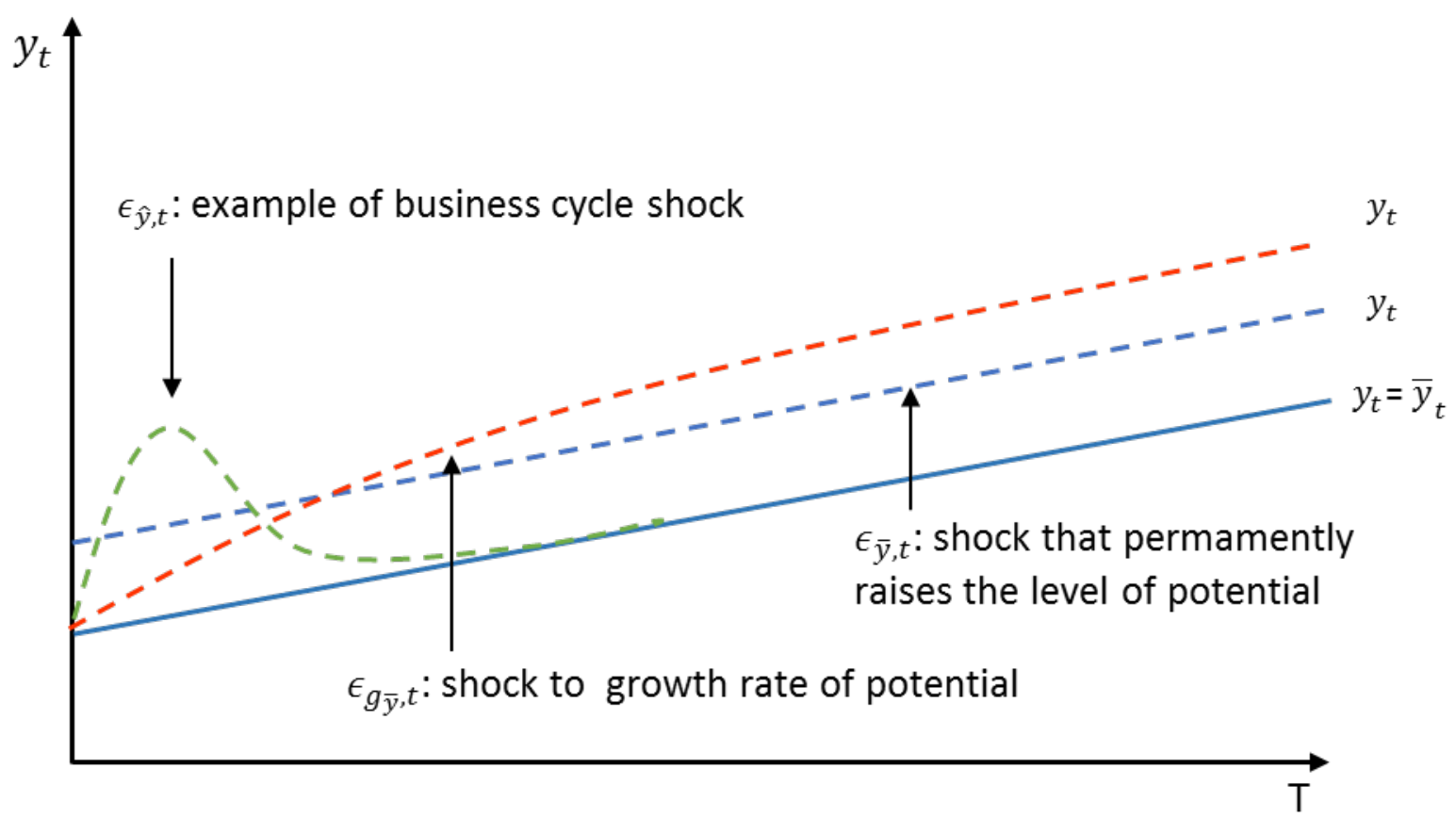

Source: Authors' construction.

In the absence of a shock, output follows its steady-state path, which is shown above by the solid blue line (which has a slope of $g_{\bar{y}}^{s s}$ ). However, any of the three shocks causes output to deviate from this path. A shock to the level $\left(\epsilon_{\bar{y}, t}\right)$ will raise (or, if negative, lower) potential output once and for all (as in the dashed blue line). A shock to the growth rate of potential $\left(\epsilon_{g_{\bar{y}}, t}\right)$, illustrated by the dashed red line, raises the growth rate of potential. However, the growth rate ultimately returns to the steady state, resulting in a rise in the level of potential output that depends on the size of the shock and the speed with which its effect decays. A shock to the output gap $\left(\epsilon_{\hat{y}, t}\right)$ causes a temporary deviation of the level of output from the level of potential, as shown by the dashed green line.

In order to help identify the three output shock terms, a Phillips Curve equation for inflation $\left(\pi_{t}\right)$ is added, which links the evolution of the output gap (an unobservable variable) to observable data on inflation, according to the process: ${ }^{8}$

\footnotetext{
${ }^{8}$ Some work suggests that the slope of the Phillips curve relationship $(\beta)$ has flattened (see for example Chapter 3 of the April 2013 World Economic Outlook). However other studies suggest that it may have steepened in
} 


$$
\pi_{t}=\lambda_{1} E_{t} \pi_{t+1}+\left(1-\lambda_{1}\right) \pi_{t-1}+\lambda_{3} \hat{y}_{t}+\epsilon_{\pi, t}-\lambda_{4} \epsilon_{\bar{y}, t}
$$

The last term allows the model to mimic the effects of shocks to productivity which lower marginal cost and therefore reduce inflation.

The inflation target, which can be time-varying, is modeled as a random walk:

$$
\pi_{t}^{T a r}=\pi_{t-1}^{T a r}+\epsilon_{\pi^{T a r}, t}
$$

The measure of inflation expectations that is used to calculate the real return on financial instruments is modeled as a linear combination of model-consistent expected inflation and lagged inflation:

$$
\pi_{t}^{e}=\beta_{1} E_{t} \pi_{t+1}+\left(1-\beta_{1}\right) \pi_{t-1}
$$

The real one-year interest rate is defined as the difference between the nominal one-year interest rate and expected inflation:

$$
r r_{t}^{1 Y}=r s_{t}^{1 Y}-\pi_{t}^{e}
$$

To close the model, we introduce a policy interest rate reaction function, where the one-year nominal interest rate responds to the deviation of inflation from target and the output gap:

$$
\begin{aligned}
& r s_{t}^{1 Y}=\alpha_{1} r s_{t-1}^{1 Y} \\
& \quad+\left(1-\alpha_{1}\right)\left[\overline{r r}_{t}^{1 Y}+\pi_{t}^{e}+\alpha_{2}\left(\pi_{t}-\pi_{t}^{T a r}\right)+\alpha_{3} \hat{y}_{t}\right]+\epsilon_{r s^{1 Y}, t}-\alpha_{4} \epsilon_{\pi^{T a r}, t}
\end{aligned}
$$

The equilibrium real interest rate is modeled as a slow-moving autoregressive process that reverts to its long-run steady-state level $(\overline{r r} S S)$.

$$
\begin{aligned}
& r r_{t}^{1 Y}=\overline{r r}_{t}^{1 Y}+\widehat{r r}_{t}^{1 Y} \\
& \overline{r r}_{t}^{1 Y}=\rho^{\overline{r^{1 Y}}} \overline{r r}_{t-1}^{1 Y}+\left(1-\rho^{\bar{r}{ }^{1 Y}}\right) \overline{r r} S S+\epsilon_{\overline{r r}^{1 Y}, t}
\end{aligned}
$$

The model allows for longer-term bond yields to shed light on the estimates of the equilibrium real interest rate. Based on the expectations theory of the term structure, the

some countries in recent years (Riggi and Venditti, 2014). Although the methodology in this paper does not allow for time variation in parameter estimates, modest changes in the estimated value of the parameter $\beta$, on its own, do not materially change the estimates of potential output and the output gap. 
interest rate on 10-year government bonds is modeled as the sum of the average expected future short-term interest rates over 10 years and a term premium.

$$
\begin{aligned}
& r s_{t}^{10 Y}=\frac{\sum_{i=t}^{t+9} r_{i}^{1 Y}}{10}+\sigma_{t}^{T e r m}+\epsilon_{r s^{10 Y}} \\
& \sigma_{t}^{T e r m}=\rho^{\sigma^{T e r m}} \sigma_{t-1}^{T e r m}+\left(1-\rho^{\sigma^{T e r m}}\right) \sigma^{\text {Term }, S S}+\epsilon_{\sigma^{t e r m}, t} \\
& \hat{u}_{t}=\bar{u}_{t}-u_{t} \\
& \bar{u}_{t}=\left(1-\rho_{\bar{u}}\right) \bar{u}_{t-1}+\rho_{\bar{u}} u^{s s}+g_{\bar{u}, t}+\epsilon_{\bar{u}, t} \\
& g_{\bar{u}, t}=\rho_{g_{\bar{u}}} g_{\bar{u}, t-1}+\epsilon_{g_{\bar{u}}, t} \\
& \hat{u}_{t}=\rho_{\hat{u}} \hat{u}_{t-1}+\tau \hat{y}+\epsilon_{\widehat{u}, t}
\end{aligned}
$$

Here, $\bar{u}_{t}$ is the equilibrium value of the unemployment rate (the NAIRU), which is time varying, and subject to shocks $\left(\epsilon_{\bar{u}, t}\right)$ and to variation in its trend $\left(g_{\bar{u}, t}\right)$, which is itself also subject to shocks $\left(\epsilon_{g_{\bar{u}}, t}\right)$. This specification allows for long-lasting deviations of the NAIRU from its steady-state value.

Most importantly, equation (34) specifies an Okun's law relationship wherein the gap between actual unemployment and its equilibrium rate (given by $\hat{u}_{t}$ ) is a function of the output gap $\left(\hat{y}_{t}\right)$.

Finally, we incorporate information from measures of capacity utilization rates in the manufacturing sector to help shed some light on the overall slack in the entire economy at a given point in time.

$$
\begin{aligned}
& \hat{c}_{t}=c_{t}-\bar{c}_{t} \\
& \bar{c}_{t}=\left(1-\delta_{2}\right) \bar{c}_{t-1}+\delta_{2} \bar{c}^{S S}+g_{\bar{c}, t}+\epsilon_{\bar{c}, t} \\
& g_{\bar{c}, t}=\left(1-\delta_{1}\right) g_{\bar{c}, t-1}+\epsilon_{g_{\bar{c}}, t} \\
& \hat{c}_{t}=\kappa \hat{y}_{t}+\epsilon_{\hat{c}, t}
\end{aligned}
$$

In the above, $\bar{c}_{t}$ is the equilibrium value of the capacity utilization rate, which changes over time, and is subject to shocks $\left(\epsilon_{\bar{c}, t}\right)$. The equilibrium capacity utilization rate grows at $g_{\bar{c}, t}$, which is itself also subject to shocks $\left(\epsilon_{g_{\bar{c}}, t}\right)$, with their impact fading gradually according to the parameter $\delta_{2}$. This specification allows for permanent movements in the equilibrium 
capacity utilization rate. The capacity utilization gap, which is meant to capture the economic slack in the manufacturing sector, should be correlated with the measure of the overall economic slack in the economy $\left(\hat{y}_{t}\right)$.

Equations (16)-(38) comprise the core of the model for the output gap and potential output. In addition, data on growth and inflation expectations are added to help identify shocks, and to improve the accuracy of the estimates at the end of the sample:

$$
\begin{aligned}
& \pi_{t+j}^{C}=\pi_{t+j}+\epsilon_{\pi^{c}, t+j}, \mathrm{j}=5 \\
& g_{, t+j}^{c}=g_{t+j}+\epsilon_{g^{c}, t}, \mathrm{j}=1, \ldots, 5
\end{aligned}
$$

For real GDP growth $(g)$, the model is augmented with forecasts from Consensus Economics for five years following the end of any particular sample of historical observations. For inflation, expectations data are added for 5-year-ahead whenever such survey data is available. These equations relate the model-consistent forward expectation for growth and inflation $\left(\pi_{t+j}\right.$ and $\left.g_{t+j}\right)$ to observable data on how various forecasts expect these variables to evolve over various horizons (one to five years ahead) at any given time $\left(g_{t+j}^{C}\right.$ and $\left.\pi_{t+j}^{C}\right)$. The 'strength' of the relationship between the survey data and the model's forward expectation is determined by the standard deviation of the error terms $\left(\epsilon_{\pi^{c}, t+j}\right.$ and $\left.\epsilon_{g^{c}, t}\right)$. In practice, setting non-zero variance of these terms allows Consensus data to influence, but not completely override, the model's expectations, particularly at the end of the sample period. In a way, the incorporation of survey data can be thought as a heuristic approach to blending forecasts from different sources and methods. The resulting impact of this information on the historical estimates of potential and the output gap can be significant, as shown in the following section. 
B. MPMOD Parameters, Shock Distribution, and Data Source

Table B1. Estimation Results for Structural Model Parameters

\begin{tabular}{|c|c|c|c|c|}
\hline \multicolumn{5}{|c|}{ Estimation Results for Structural Model Parameters } \\
\hline & \multicolumn{2}{|c|}{ Mode } & \multicolumn{2}{|c|}{ Standard Error } \\
\hline & Prior & Posterior & Prior & Posterior \\
\hline$\rho_{g_{\bar{y}}}$ & 0.2912 & 0.2808 & 0.0087 & 0.0079 \\
\hline$\phi_{1}$ & 0.6713 & 0.6582 & 0.2014 & 0.0134 \\
\hline$\phi_{2}$ & 0.4000 & 0.3920 & 0.1200 & 0.0161 \\
\hline$\phi_{3}$ & 0.4000 & 0.4092 & 0.1200 & 0.0124 \\
\hline$\phi_{4}$ & 0.3000 & 0.2971 & 0.0900 & 0.0182 \\
\hline$\phi_{5}$ & 0.8000 & 0.8150 & 0.3000 & 0.0345 \\
\hline$\lambda_{1}$ & 0.4101 & 0.4101 & 0.0012 & 0.0012 \\
\hline$\lambda_{3}$ & 0.0822 & 0.0858 & 0.0025 & 0.0024 \\
\hline$\lambda_{4}$ & 0.1000 & 0.0977 & 0.6000 & 0.0286 \\
\hline$\beta_{1}$ & 0.4000 & 0.4005 & 0.0012 & 0.0012 \\
\hline$\alpha_{1}$ & 0.5000 & 0.5006 & 0.0015 & 0.0015 \\
\hline$\alpha_{2}$ & 1.5000 & 1.5013 & 0.0045 & 0.0044 \\
\hline$\alpha_{3}$ & 0.0500 & 0.0567 & 0.0150 & 0.0111 \\
\hline$\alpha_{4}$ & 2.0000 & 1.9491 & 0.6000 & 0.0283 \\
\hline 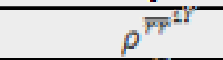 & 0.9000 & 0.8985 & 0.2700 & 0.0154 \\
\hline$\rho^{\sigma^{T / n m}}$ & 0.7000 & 0.6855 & 0.0210 & 0.0148 \\
\hline $\bar{\tau}$ & 0.5213 & 0.5233 & 0.1564 & 0.0255 \\
\hline$\rho_{\hat{\mathrm{u}}}$ & 0.4073 & 0.4214 & 0.1222 & 0.0270 \\
\hline$\rho_{\bar{u}}$ & 0.1197 & 0.1266 & 0.0359 & 0.0252 \\
\hline$\rho_{g_{\bar{u}}}$ & 0.1202 & 0.1208 & 0.0036 & 0.0036 \\
\hline$\delta_{1}$ & 0.1000 & 0.1081 & 0.0300 & 0.0269 \\
\hline$\delta_{2}$ & 0.2000 & 0.1826 & 0.0600 & 0.0257 \\
\hline$\kappa$ & 2.1670 & 2.1765 & 0.6501 & 0.0446 \\
\hline
\end{tabular}

Source: Authors' estimates. 
Table B2. Estimation Results for Shock Distributions

\begin{tabular}{|c|c|c|c|c|}
\hline \multicolumn{5}{|c|}{ Estimation Results for Shock Distribution } \\
\hline & \multicolumn{2}{|c|}{ Mode } & \multicolumn{2}{|c|}{ Standard Error } \\
\hline & Prior & Posterior & Prior & Posterior \\
\hline$\sigma\left(\epsilon_{y, t}\right)_{c f^{1}}$ & 1.5000 & 1.4108 & 0.0750 & 0.0762 \\
\hline$\sigma\left(\epsilon_{y, t}\right)_{c f^{2 y}}$ & 1.5000 & 1.4022 & 0.0750 & 0.0770 \\
\hline$\sigma\left(\epsilon_{y, t}\right)_{c f^{3 y}}$ & 1.5000 & 1.4068 & 0.0750 & 0.0768 \\
\hline$\sigma\left(\epsilon_{y, t}\right)_{c f^{4 y}}$ & 1.5000 & 1.4009 & 0.0750 & 0.0771 \\
\hline$\sigma\left(\epsilon_{y, t}\right)_{c f^{5 y}}$ & 1.5000 & 1.3975 & 0.0750 & 0.0773 \\
\hline$\sigma\left(\epsilon_{\pi, t}\right)_{c f^{1 y}}$ & 1.0000 & 0.9398 & 0.0500 & 0.0509 \\
\hline$\sigma\left(\epsilon_{\pi, t}\right)_{c f^{2 y}}$ & 1.0000 & 0.9333 & 0.0500 & 0.0514 \\
\hline$\sigma\left(\epsilon_{\pi, t}\right)_{c f^{3 y}}$ & 1.0000 & 0.9279 & 0.0500 & 0.0519 \\
\hline$\sigma\left(\epsilon_{\pi, t}\right)_{c f^{4 y}}$ & 1.0000 & 0.9263 & 0.0500 & 0.0520 \\
\hline$\sigma\left(\epsilon_{\pi, t}\right)_{c f^{5 y}}$ & 1.0000 & 0.9269 & 0.0500 & 0.0519 \\
\hline$\sigma\left(\epsilon_{\bar{y}, t}\right)$ & 0.0711 & 0.0692 & 0.0036 & 0.0035 \\
\hline$\sigma\left(\epsilon_{g_{\bar{y}}, t}\right)$ & 0.1544 & 0.1783 & 0.0077 & 0.0068 \\
\hline$\sigma\left(\epsilon_{y, t}\right)$ & 0.8038 & 0.8153 & 0.0402 & 0.0166 \\
\hline$\sigma\left(\epsilon_{\pi, t}\right)$ & 0.6834 & 0.6673 & 0.0308 & 0.0166 \\
\hline$\sigma\left(\epsilon_{\pi^{T a r}, t}\right)$ & 0.0804 & 0.0992 & 0.0040 & 0.0033 \\
\hline$\sigma\left(\epsilon_{r s^{1 Y}, t}\right)$ & 0.4019 & 0.4196 & 0.0201 & 0.0127 \\
\hline$\sigma\left(\epsilon_{\overline{r r}}{ }^{1 Y}{ }_{t}\right)$ & 0.1000 & 0.1154 & 0.0050 & 0.0045 \\
\hline$\sigma\left(\epsilon_{r S^{10 Y}}\right)$ & 0.4019 & 0.4104 & 0.0201 & 0.0156 \\
\hline$\sigma\left(\epsilon_{\sigma^{t e r m}, t}\right)$ & 0.3000 & 0.3138 & 0.0150 & 0.0125 \\
\hline$\sigma\left(\epsilon_{\widehat{u}, t}\right)$ & 0.4976 & 0.4944 & 0.0249 & 0.0244 \\
\hline$\sigma\left(\epsilon_{\bar{u}, t}\right)$ & 0.0249 & 0.0249 & 0.0012 & 0.0012 \\
\hline$\sigma\left(\epsilon_{g_{\bar{u}}, t}\right)$ & 0.0248 & 0.0250 & 0.0012 & 0.0012 \\
\hline$\sigma\left(\epsilon_{\bar{c}, t}\right)$ & 0.4003 & 0.4044 & 0.0200 & 0.0172 \\
\hline$\sigma\left(\epsilon_{g_{\bar{c}}, t}\right)$ & 0.4043 & 0.4124 & 0.0202 & 0.0195 \\
\hline$\sigma\left(\epsilon_{\hat{c}, t}\right)$ & 2.2735 & 2.2337 & 0.1137 & 0.1034 \\
\hline cf denotes & $\begin{array}{l}\text { eviat } \\
\text { oreca }\end{array}$ & & & \\
\hline
\end{tabular}

Source: Authors' estimates. 
Table B3. Data Sources

\begin{tabular}{l|l}
\hline Indicator & Source \\
\hline \hline Inflation Expectations & Consensus Economics; CBO \\
Gross Domestic Product Growth Expectations (Constant Prices) & Consensus Economics \\
Gross Domestic Product (Constant Prices) & U.S Bureau of Economic Analysis \\
CPI Inflation & U.S Bureau of Labor Statistics \\
Unemployment Rate & U.S Bureau of Labor Statistics \\
Capacity Utilization & Federal Reserve \\
One-Year Treasury Constant Maturity Rate & Federal Reserve \\
$10-Y e a r$ Treasury Constant Maturity Rate & Federal Reserve \\
\hline
\end{tabular}


C. RMSE of Consensus Forecasts

Figure C1. RMSE of Consensus Forecasts

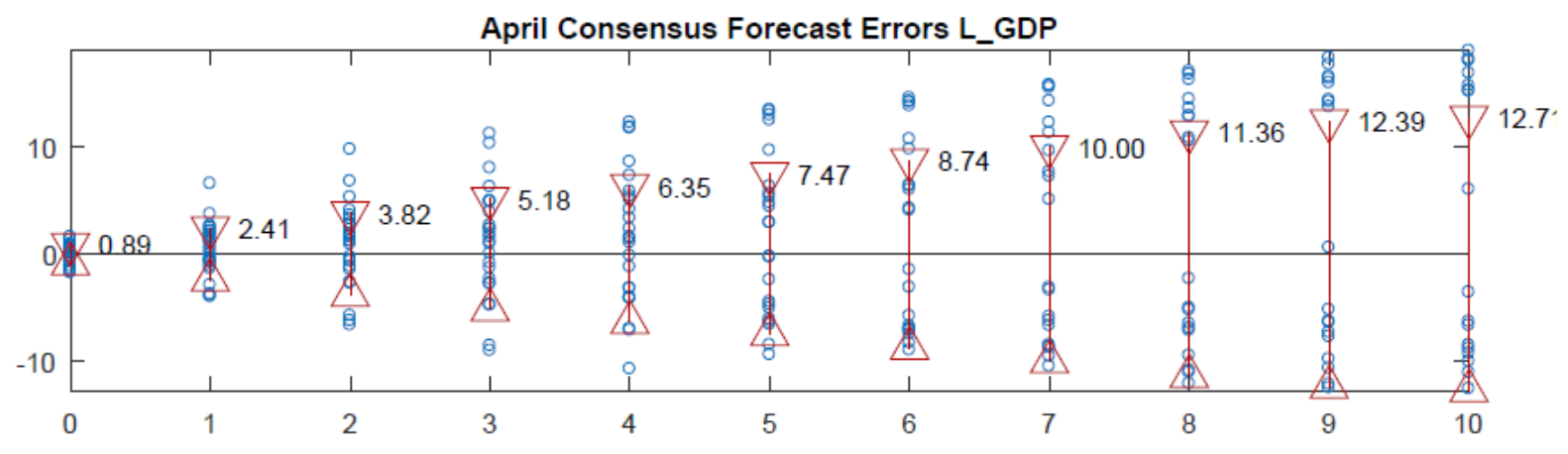

April Consensus Forecast Errors DL_GDP
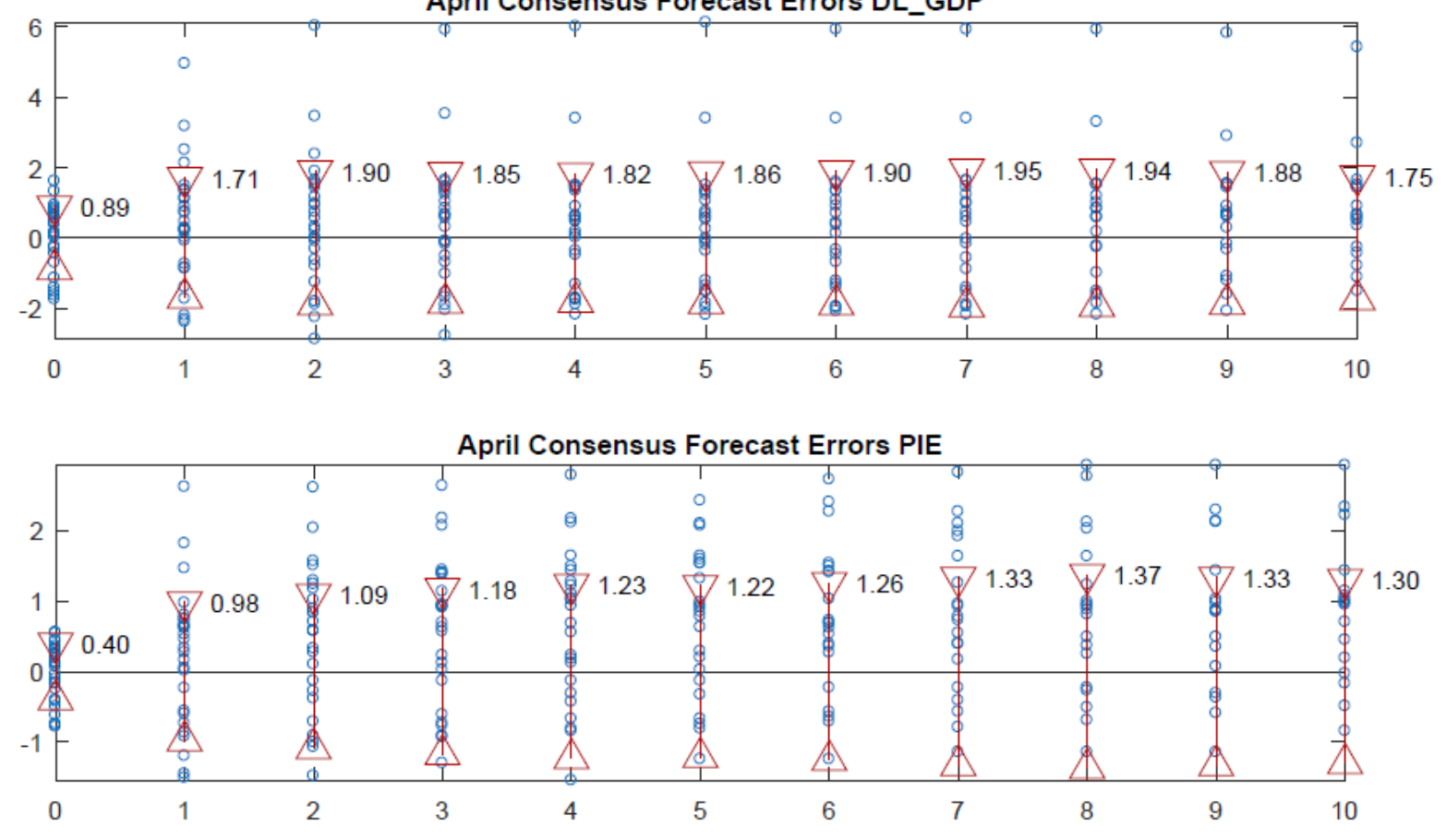

Source: Authors' estimates. 